\title{
On the Correspondence between Short- and Long-Time-Scale Systematic Errors in CAM4/CAM5 for the Year of Tropical Convection
}

\author{
Shaocheng Xie, Hsi-Yen Ma, James S. Boyle, Stephen A. Klein, And Yuying Zhang \\ Lawrence Livermore National Laboratory, Livermore, California
}

(Manuscript received 7 March 2012, in final form 24 May 2012)

\begin{abstract}
The correspondence between short- and long-time-scale systematic errors in the Community Atmospheric Model, version 4 (CAM4) and version 5 (CAM5), is systematically examined. The analysis is based on the annual-mean data constructed from long-term "free running" simulations and short-range hindcasts. The hindcasts are initialized every day with the ECMWF analysis for the Year(s) of Tropical Convection. It has been found that most systematic errors, particularly those associated with moist processes, are apparent in day 2 hindcasts. These errors steadily grow with the hindcast lead time and typically saturate after five days with amplitudes comparable to the climate errors. Examples include the excessive precipitation in much of the tropics and the overestimate of net shortwave absorbed radiation in the stratocumulus cloud decks over the eastern subtropical oceans and the Southern Ocean at about $60^{\circ} \mathrm{S}$. This suggests that these errors are likely the result of model parameterization errors as the large-scale flow remains close to observed in the first few days of the hindcasts. In contrast, other climate errors are present in the hindcasts, but with amplitudes that are significantly smaller than and do not approach their climate errors during the 6-day hindcasts. These include the cold biases in the lower stratosphere, the unrealistic double-intertropical convergence zone pattern in the simulated precipitation, and an annular mode bias in extratropical sea level pressure. This indicates that these biases could be related to slower processes such as radiative and chemical processes, which are important in the lower stratosphere, or the result of poor interactions of the parameterized physics with the large-scale flow.
\end{abstract}

\section{Introduction}

Despite recent advances made in climate modeling, large systematic errors are still present in their simulated mean state of climate (Randall et al. 2007). Some of these errors, such as the unrealistic double-intertropical convergence zone (ITCZ) pattern with the simulated tropical precipitation, are long-standing problems and have been shown in different generations of climate models. Reducing systematic errors in the mean state is important since they can affect both tropical variability like the El Niño-Southern Oscillation (ENSO) and the Madden-Julian oscillation (MJO) and model climate sensitivity and future climate projection. However, fully understanding the cause of these systematic errors in a climate system is difficult since the climate system is

Corresponding author address: Shaocheng Xie, Atmospheric, Earth and Energy Division (L-103), Lawrence Livermore National Laboratory, P.O. Box 808, Livermore, CA 94550.

E-mail: xie2@llnl.gov a complicated nonlinear system and climate errors could be the compensated result from errors in representing various dynamical and physical processes in climate models.

To better understand systematic climate errors, the weather forecast approach was proposed to be used in evaluating climate models so that model errors could be identified before longer time-scale feedbacks develop (Phillips et al. 2004; Rodwell and Palmer 2007). In this approach, climate models are run in "weather forecast mode" with initial data from multiple numerical weather prediction (NWP) center analyses or reanalyses. The major assumptions behind this approach are 1) the large-scale state of the atmosphere in the early periods of a forecast is realistic enough that errors may be ascribed to the parameterizations of atmospheric processes and 2) atmospheric physical processes (e.g., moist process) are often fast ( $\sim$ hours) and the large-scale state changes slowly ( $\sim$ days). Using the weather forecast approach also helps assess how soon climate errors develop and facilitate the comparison to detailed process 
observations. The advantage of using the weather forecast approach in understanding systematic error in climate models has led to a major international multimodel intercomparison project-the Transpose-Atmospheric Model Intercomparison Project (AMIP) (http://www. transpose-amip.info), which runs the Coupled Model Intercomparison Project phase 5 (CMIP5) climate models in weather forecast mode with the goal to better understand and yield significant insights into the cause of errors in these models.

Previous studies using the weather forecast approach to evaluate climate errors have shown some evidence of the correspondence between errors in the short-range weather forecasts and errors in the long-term climate simulations of the same model (Xie et al. 2004; Klein et al. 2006; Boyle et al. 2008; Williams and Brooks 2008; Martin et al. 2010). This indicates that some systematic errors in climate simulations could be detected in the early stage of model integration. This has important implications in studies of these model errors since running the climate model in NWP mode allows us to perform a more indepth analysis during a short time period where more observations are available and different model errors from various processes have not been compensated.

In this study, we systematically examine the relationship between composite errors in the short-range hindcasts and long-term climate simulations exhibited in the latest versions of the National Center for Atmospheric Research (NCAR) and the Department of Energy (DOE) Community Atmospheric Model, version 4 (CAM4) and version 5.1 (CAM5), with the goal to clarify over what time scales model systematic errors develop. Note that exploring the correspondence between short and long time-scale systematic errors in various moistassociated fields in complex climate models has not been done systematically and globally in previous studies to our best knowledge. Such a study can provide essential clues to the origins of these errors. Both similarities and differences between hindcasts and climate integrations are of interest since the similarities may indicate errors that are directly the result of parameterization errors as the large-scale flow remains close to observed, whereas differences could reflect errors that develop once incorrect states and circulations have developed owing to their poor interactions with the parameterized physics.

The hindcast data are from a series of 6-day hindcasts with CAM4 and CAM5 initialized at 0000 UTC every day from the European Center for Medium-Range Weather Forecasts (ECMWF) analysis for the Year of Tropical Convection (YOTC) (from May 2008 to April 2010) period. These hindcasts are performed under the DOE Cloud-Associated Parameterizations Test bed (CAPT) (Phillips et al. 2004), which provides a flexible environment for running climate models in NWP mode. The YOTC project, sponsored by the World Climate Research Programme (WCRP) and the World Weather Research Programme (WWRP)/The Observing System Research and Predictability Experiment (THORPEX), was established to address the grand challenge that current global atmospheric models face in realistically representing tropical convection through an international effort of coordinated observing, modeling, and forecasting of organized tropical convection and its influences on predictability (Waliser et al. 2012; Moncrieff et al. 2012). The long-term data are from an ensemble of "free running" simulations with CAM4 and CAM5 following the prototype described in AMIP II (Gates et al. 1999) but forced by the observed weekly sea surface temperature (SST) for 2008-10, the YOTC period. The ensemble of the AMIP runs consists of three ensemble members with each starting from a slightly different initial condition to address potential model sensitivity to initial conditions. These free-running 3-yr AMIP runs are conducted to improve the comparison to the 6-day hindcasts over the same period. It should be mentioned that the systematic errors exhibited from the ensemble of the 3-yr AMIP runs, as being discussed in this paper, are very similar to those shown in the 20-yr AMIP runs, which are available from the NCAR Community Earth System Model (CESM) website (http://www.cesm.ucar.edu/experiments/cesm1.0/). This indicates that errors shown in the free-running AMIP simulations are representative of climate errors exhibited in CAM4 and CAM5 climate runs.

Section 2 of this paper gives more details about the models and observational data used in this study. Section 3 provides a discussion of CAM4 and CAM5 simulated tropical general circulation, precipitation, clouds, and radiation in both hindcasts and climate simulations. Summary and future work are present in section 4 .

\section{Model, experimental details, and observations}

The models examined in this study are the NCAR CAM4 (Neale et al. 2012, manuscript submitted to J. Climate) and CAM5 (Neale et al. 2010). CAM4 was released in April 2010 and was used for Intergovernmental Panel on Climate Change (IPCC) Fifth Assessment Report (AR5) simulations. Compared to its earlier versions, one important improvement in CAM4 is in its deep convection scheme, originally developed by Zhang and McFarlane (1995). The calculation of convective available potential energy (CAPE) has been reformulated to include more realistic dilution effects through an explicit representation of entrainment. Additionally, the convective momentum transport (CMT) has been 
included in the parameterization of deep convection. These two changes have resulted in a significant improvement in many aspects of simulated tropical convection (Neale et al. 2008).

CAM5 is the latest version of CAM, which contains a range of significant enhancements and improvements in the representation of physical processes. Almost all of the physical parameterizations in CAM4 have been changed in CAM5 except for the deep convection scheme. This includes the following: 1) a new moist turbulence scheme explicitly simulates stratus-radiationturbulence interactions, making it possible to simulate full aerosol indirect effects within stratus (Bretherton and Park 2009); 2) a new shallow convection scheme uses a realistic plume dilution equation and closure that accurately simulates the spatial distribution of shallow convective activity (Park and Bretherton 2009); 3) a new two-moment cloud microphysics scheme for stratiform clouds (Morrison and Gettelman 2008), which allows ice supersaturation and features activation of aerosols to form cloud drops and ice crystals; 4) a new radiation scheme, the rapid radiative transfer method for GCMs (RRTMG), which employs an efficient and accurate correlated-k method for calculating radiative fluxes and heating rates (Iacono et al. 2000; Mlawer et al. 1997). In addition, a three-mode modal aerosol module (MAM3) has been implemented in CAM5 to provide internally mixed representations of number concentrations and mass for Aitkin, accumulation, and course aerosol modes (Liu et al. 2012). These major physics enhancements permit new research capability for assessing the impact of aerosol on cloud properties. In particular, they provide a physically based estimate of the impact of anthropogenic aerosol emissions on the radiative forcing of climate by clouds.

Both CAM4 and CAM5 with their finite volume dynamic core at a resolution of $0.9^{\circ} \times 1.25^{\circ}$ in the horizontal are used in this study. In the vertical, CAM4 has 26 levels while CAM5 uses 30 levels in order to benefit from the new planetary boundary layer and shallow convection schemes. Both models are initialized from the ECMWF analysis data for the YOTC period. The analysis data are interpolated from the finer-resolution analysis grid of $0.15^{\circ}$ and 91 levels to the CAM4/CAM5 grids using the procedures described by Boyle et al. (2005). These procedures use a slightly different interpolation approach for each of the dynamic state variables: that is, horizontal winds, temperature, specific humidity, and surface pressure along with careful adjustments to account for the difference in representation of the earth's topography between models.

A series of 6-day hindcasts are initialized every day at 0000 UTC from the ECMWF analysis for the entire
YOTC period from 1 May 2008 to 30 April 2010. Composite errors are calculated using day 1 to day 6 hindcasts in order to examine how systematic errors evolve with time. An ensemble of free running 3-yr AMIP-type runs with the CAM4 and CAM5 forced by observed weekly SST is conducted for the 3-yr period from 2008 to 2010 to compare with these hindcast runs. The ensemble of the AMIP runs consists of three ensemble members with each starting from a slightly different initial condition to address potential model sensitivity to initial conditions.

The data used to evaluate model performance include precipitation from the National Aeronautics and Space Administration (NASA)/Tropical Rainfall Measuring Mission (TRMM) (Simpson et al. 1988), clouds from the Cloud-Aerosol lidar and Infrared Pathfinder Satellite (CALIPSO) (Winker et al. 2003), radiation fluxes from the Clouds and the Earth's Radiant Energy System (CERES) observations (Wielicki et al. 1996), and the large-scale state variables from the ECMWF operational analysis. To improve the comparison between model clouds and satellite observations, output from the CALIPSO simulator (Bodas-Salcedo et al. 2011) embedded in CAM4 and CAM5 is used to compare with the corresponding satellite observations.

\section{Hindcasts versus climate simulations}

The focus of our following analysis is on those wellknown climate biases that are exhibited in both the CAM models and many other climate models. The model errors are calculated according to the available observations or the ECMWF analysis as described in section 2. For most of the cases, we only show day 2 and day 5 hindcasts. Day 2 hindcasts are selected to reduce the impact of model spinup that may occur in the first few hours of integration, especially in the tropics. Day 5 hindcasts are used to demonstrate how model errors evolve with the hindcast lead time. The composite of day 2 hindcasts is calculated from averaging a series of 2448-h hindcasts over a selected period. The same is true for day 5 hindcasts, which are the composite of 96-120-h hindcasts. The AMIP results discussed below are based on the mean of the three-member ensemble of AMIP runs. A comparison among these three AMIP runs indicates that the model errors shown in these AMIP runs are very similar to each other and are not sensitive to the slightly different initial conditions. In this paper, we emphasize our discussion on annualmean errors based on the data from the complete year of 2009 within the YOTC period. Note that the weather and climate of 2009 were influenced by a moderate El Niño, which strengthened in the fall of 2009 and through 

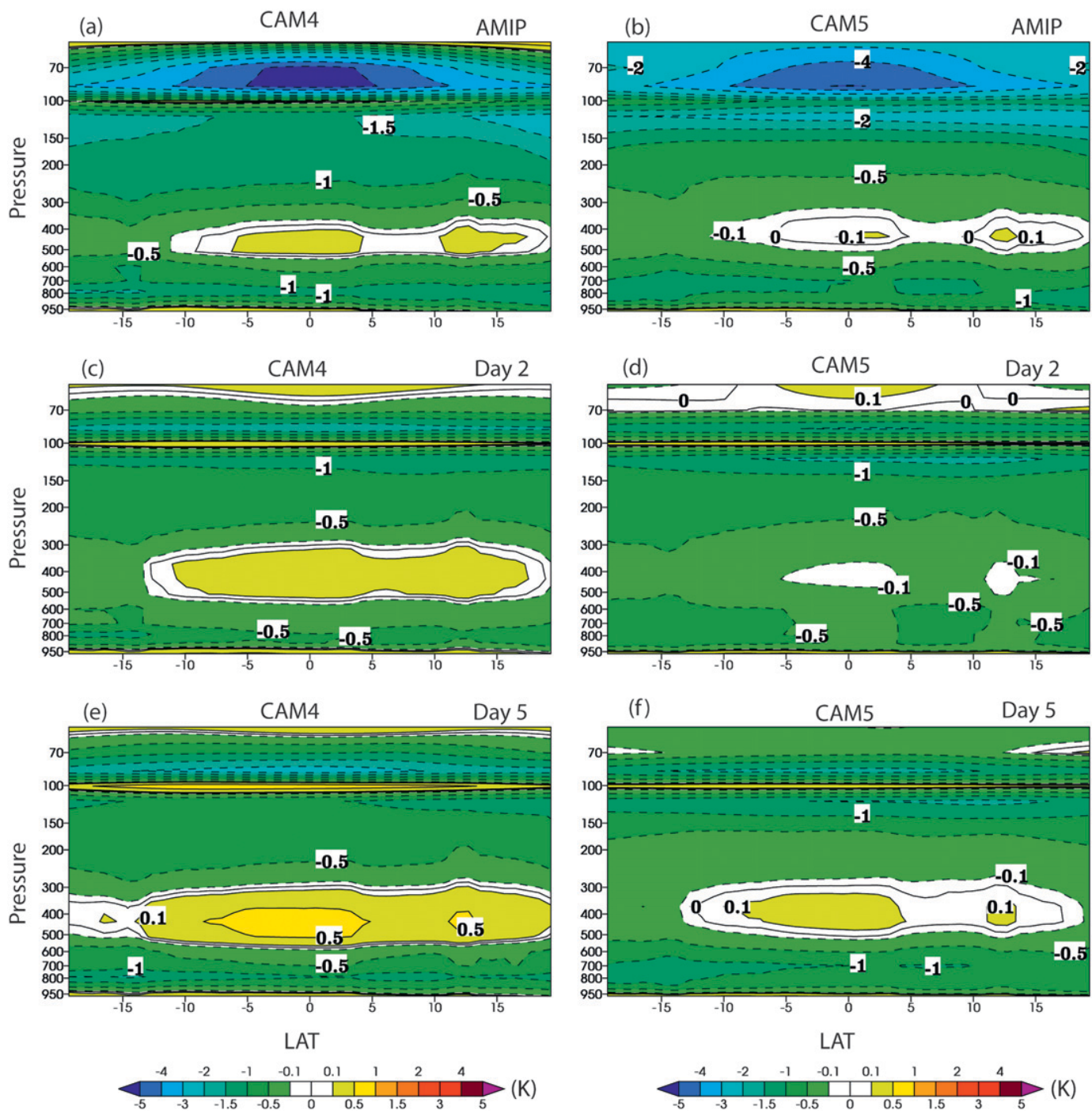

FIG. 1. Difference in the annual and zonal mean temperature between different types of model runs and the ECMWF analysis for the year 2009 over the tropics $\left(20^{\circ} \mathrm{S}-20^{\circ} \mathrm{N}\right)$ : (a) CAM4 AMIP run, (b) CAM5 AMIP run, (c) CAM4 day 2 hindcasts, and (d) CAM5 day 2 hindcasts, (e) CAM4 day 5 hindcasts, and (f) CAM5 day 5 hindcasts.

the 2009/10 Northern Hemisphere winter. Seasonal errors have been examined and they also exhibit similar correspondence.

\section{a. Mean state errors in tropical general circulation}

Figure 1 displays the difference in the annual and zonal mean temperature between the model runs and the ECMWF analysis. A well-known error in climate models is the persistent cold bias near the tropical tropopause and in the lower stratosphere (Hamilton et al. 1995; Hack et al. 1998). It is believed to be the result of some complex interaction among clouds, radiation, and chemical processes as well as interaction between troposphere and stratosphere. Boville et al. (2006) showed that this error is partially related to problems in representing the subvisible cirrus clouds near the tropopause. Radiative and chemical processes are also important in the lower stratosphere. Similar cold bias (larger than $4 \mathrm{~K}$ ) is found in both CAM4 and CAM5 AMIP runs in which the biases persist throughout the seasonal cycle. The cold bias maxima are seen between 100 and $75 \mathrm{hPa}$ right above the equator. However, the error is considerably smaller in CAM5 compared to CAM4. In the tropical troposphere (below $100 \mathrm{hPa}$ ), the AMIP runs generally show small cold biases except for the levels between 400 and $500 \mathrm{hPa}$ where small warm biases are found, which are likely related to the excessive precipitation produced by the models over much of the tropics, as being shown in the next section. The errors shown in the AMIP runs are apparent in their day 2 

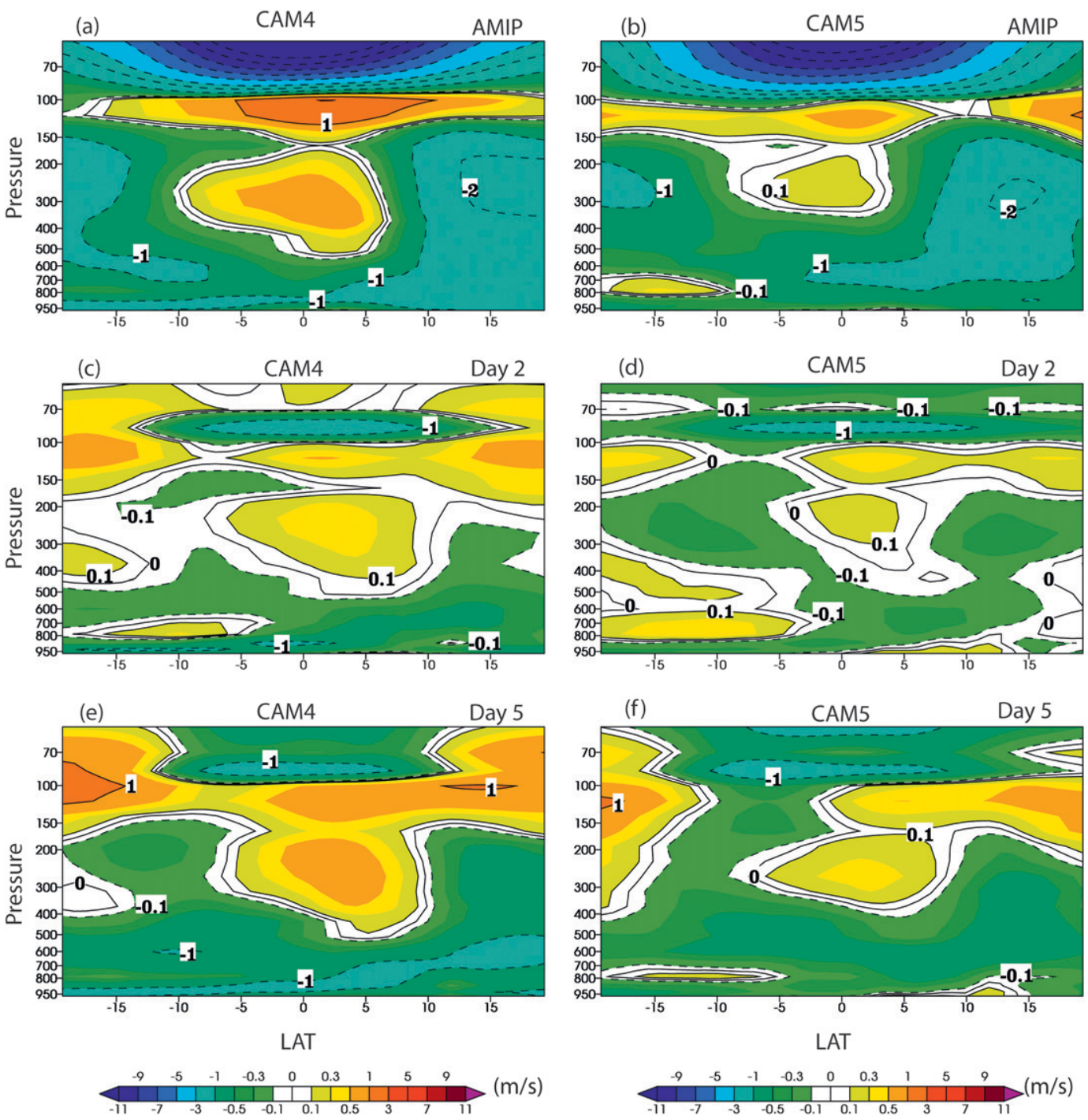

FIG. 2. As in Fig. 1, but for zonal winds.

and day 5 hindcasts. However, the magnitude of the cold bias near the tropical tropopause and in the lower stratosphere is significantly smaller in the hindcasts (typically less than $2 \mathrm{~K}$ ), suggesting a longer time is needed for the upper-atmospheric cold bias to fully develop. In contrast, the hindcast errors are typically comparable to the climate errors in the troposphere. It is noted that the midtropospheric warm bias appears larger in day 5 hindcasts than in the AMIP runs. The larger warm bias in day 5 hindcasts indicates that deficiencies with the model moist processes are exaggerated in the forecasts. By comparing the day 2 and day 5 composite errors, there is a tendency that these errors steadily evolve with time. Near the tropopause $(\sim 100 \mathrm{hPa})$ a warm bias is seen on a single model layer. This is most likely due to the difference in model vertical resolution used in CAM and ECMWF that causes slight difference in the model-defined tropopause height in these two models.

Figure 2 is as in Fig. 1 but for the annual and zonal mean zonal winds. A typical error for climate models is the westerly bias in the tropical mid and upper troposphere above the equator. This problem is shown between 300 and $100 \mathrm{hPa}$ in CAM4 and CAM5 in both the AMIP runs and their hindcasts for all seasons. The magnitude of the westerly bias is comparable between the AMIP runs and the hindcasts while it is smaller in CAM5 compared to CAM4. In comparison with the CAM5 AMIP runs, the westerly bias in the CAM5 day 2 and day 5 hindcasts slightly shifts northward near the equator. Again, the error grows with the hindcast lead time. It is interesting to see that both CAM 4 and CAM5 AMIP runs significantly 

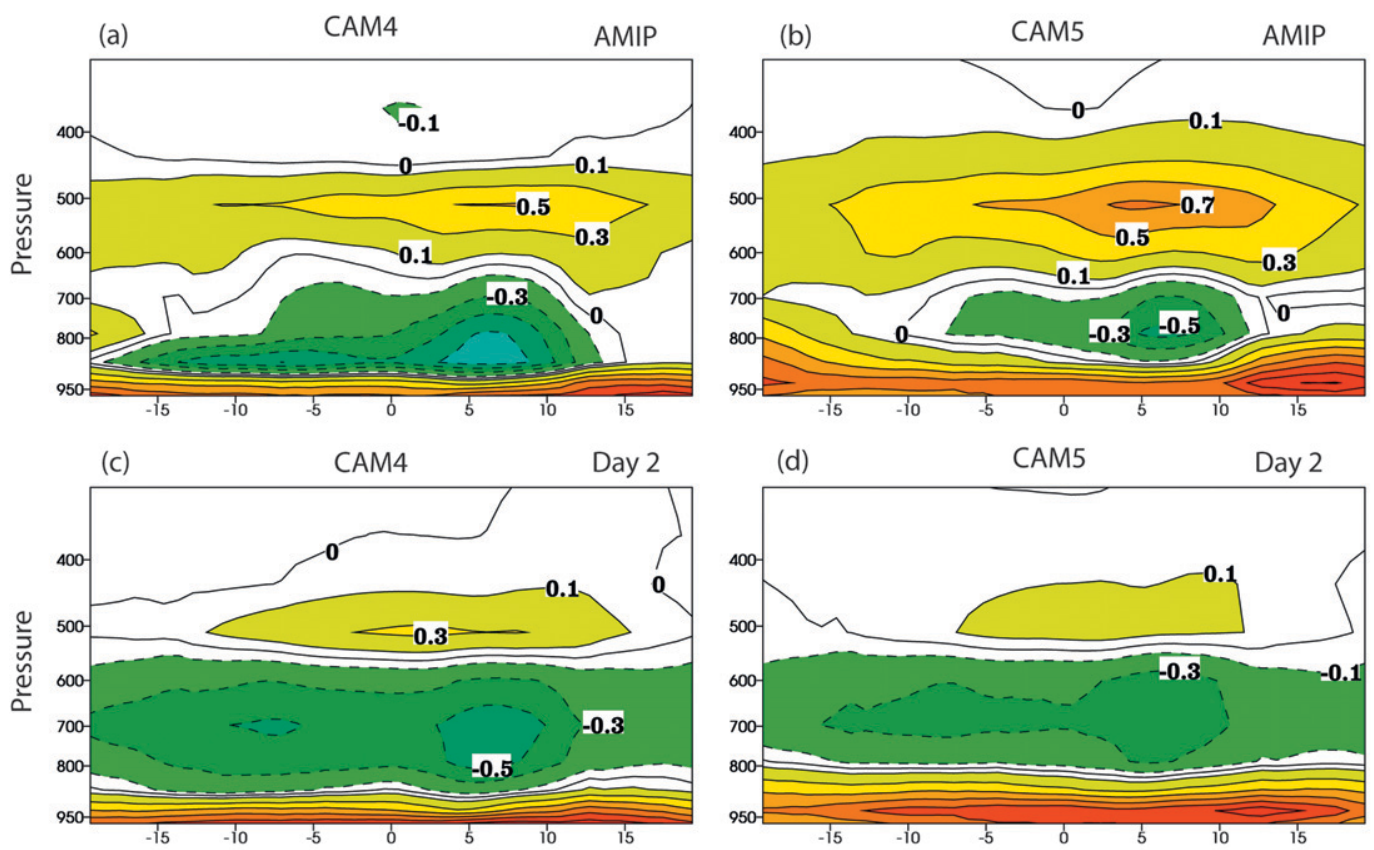

(d)

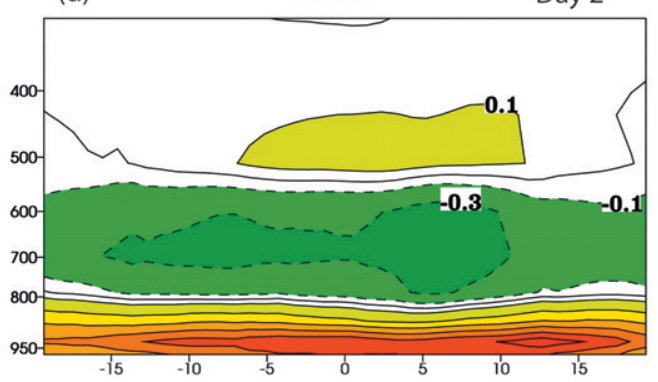

(e)

CAM4
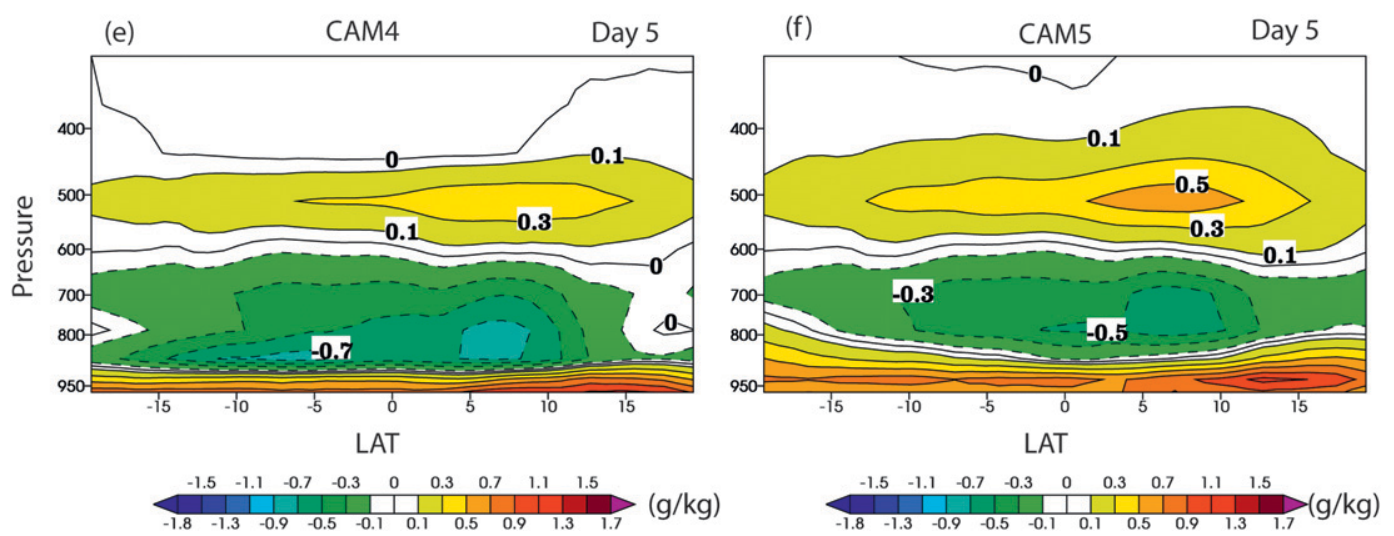

FIG. 3. As in Fig. 1, but for specific humidity.

underestimate the westerlies in the stratosphere, where the problem is not clear in their hindcast runs.

For specific humidity (Fig. 3), the model errors in the AMIP runs for both models and their hindcasts are remarkably similar. Both show a significant moist bias (larger than $1 \mathrm{~g} \mathrm{~kg}^{-1}$ ) near the surface, a moderate dry bias $\left(\sim 0.5 \mathrm{~g} \mathrm{~kg}^{-1}\right)$ in the lower troposphere, and a moderate moist bias (up to $0.7 \mathrm{~g} \mathrm{~kg}^{-1}$ ) in the middle troposphere near $500 \mathrm{hPa}$. This moist-dry-moist bias in the vertical was also found in an earlier version of the CAM (CAM2) and investigated using a very similar methodology by Williamson et al. (2005). These biases develop quickly in just 2-day hindcasts, indicating that it must be related to deficiencies in modeled atmospheric moist processes such as cumulus convection. The large moist bias near the surface suggests that the models could not effectively transport moisture from the boundary layer to the free troposphere.

For relative humidity (Fig. 4), a prominent error is the dry bias seen in the upper troposphere between 100 and $200 \mathrm{hPa}$ for both the AMIP runs and the hindcasts. For the AMIP runs, typical error amplitudes in the upper troposphere are $10 \%-15 \%$ in CAM 4 and $5 \%-10 \%$ in CAM5, indicating the improvement made by the new model. Another significant moist bias is seen in the midtroposphere with the peak near $500 \mathrm{hPa}$ in the AMIP runs for both models, consistent with the moist bias shown in the specific humidity field (Fig. 3) around similar layers. It is noticed that CAM5 has a much larger moist bias $(>10 \%)$ than CAM4. By comparing to CALIPSO observations (shown later) this may be related to the fact that CAM5 has produced more midlevel 

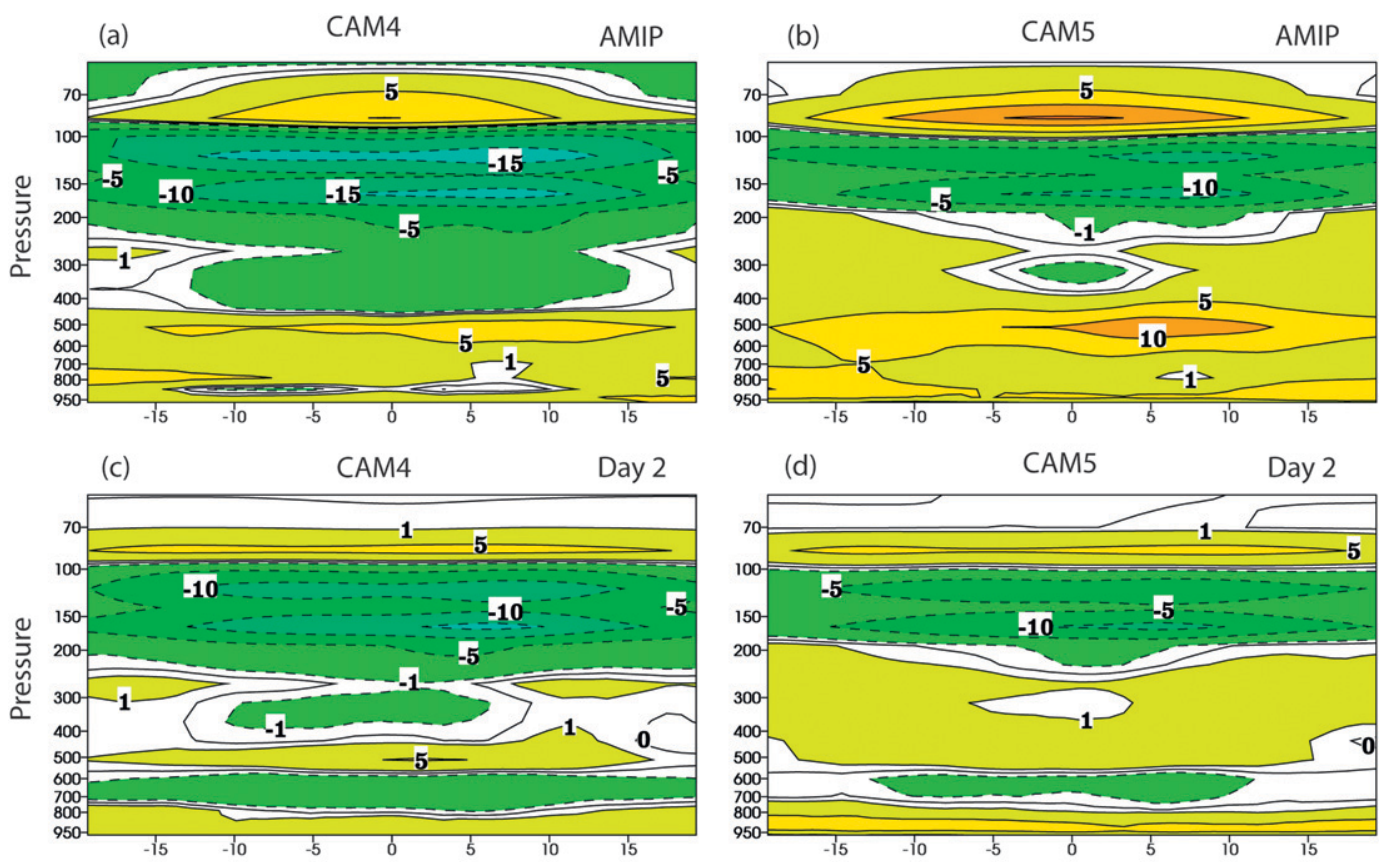

(d)
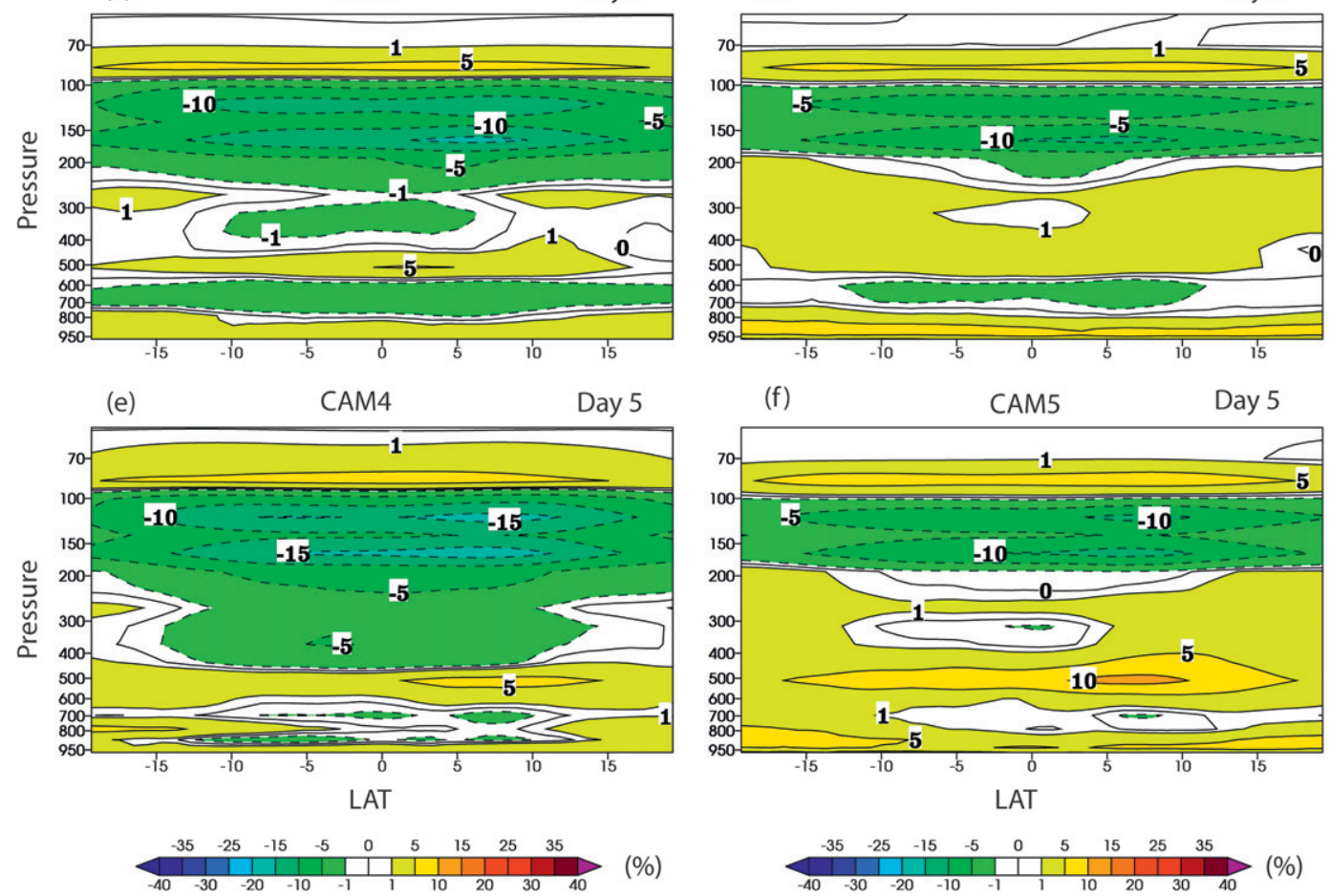

FIG. 4. As in Fig. 1, but for relative humidity.

clouds than CAM4. As for temperature and zonal winds, the climate errors in relative humidity $(\mathrm{RH})$ are evident in their hindcast runs. It is noticed that the midtroposphere moist bias is not clear in their day 2 hindcasts (Figs. 4c,d), while it is clearly seen in their day 5 hindcasts (Figs. 4e,f) with similar error amplitudes to their AMIP runs. In the lower stratosphere, both CAM4 and CAM5 exhibit a moist bias of larger than $5 \%$, which appears to be associated with the cold bias in their temperature simulations. In contrast, this moist bias is much smaller in their hindcasts.

The above results demonstrate the strong correspondence between short- and long-term errors in the tropical large-scale circulation, especially after a few day hindcasts (e.g., 5 day hindcasts). The hindcast and climate biases are comparable in the troposphere while the former is significantly smaller than the latter near the tropopause or in the lower stratosphere where radiative and chemical processes are important and vertical transport and mixing are weak. This suggests that the large model climate errors seen near the tropopause or in the lower stratosphere need a much longer time scale to fully develop. The errors in the troposphere can develop fast, such as in a few days hindcasts, primarily because the tropical troposphere is largely influenced by moist processes such as clouds and precipitation, which are often fast ( $\sim$ hours). Systematic errors in these moist process related fields are examined next.

\section{b. Tropical precipitation, clouds, and radiation}

Tropical precipitation accounts for more than twothirds of the global precipitation falling to the earth. The 

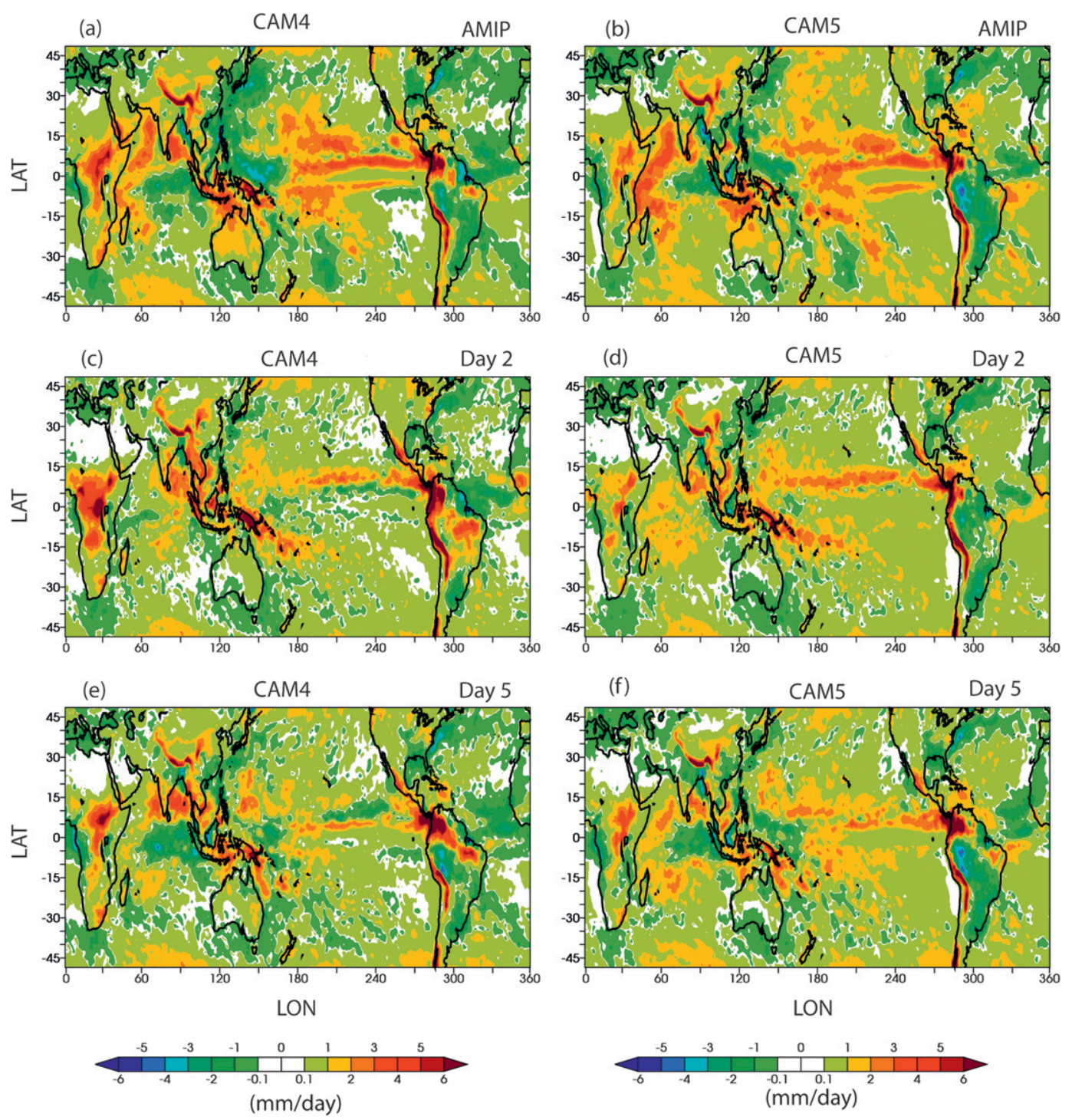

FIG. 5. Difference in the annual-mean surface precipitation between different types of model runs and the TRMM observations for the year 2009 over the tropics and midlatitudes $\left(49^{\circ} \mathrm{S}-49^{\circ} \mathrm{N}\right)$ : (a) CAM4 AMIP run, (b) CAM5 AMIP run, (c) CAM4 day 2 hindcasts, and (d) CAM5 day 2 hindcasts, (e) CAM4 day 5 hindcasts, and (f) CAM5 day 5 hindcasts.

latent heat released by the tropical precipitation is a major energy source for the large-scale circulation. However, it has been difficult for current climate models to correctly simulate tropical precipitation mainly because convection happens on scales unresolved by the models. Many long-standing climate errors are associated with model deficiencies in simulating tropical convection, such as the unrealistic double-ITCZ pattern with the simulated tropical precipitation that has been shown in different generations of climate models. In this section, we will discuss how these climate biases in precipitation, clouds, and radiation correspond to their short-range hindcasts.
The difference in the annual-mean surface precipitation between the model runs and the TRMM observations is displayed in Fig. 5. Note that the TRMM data are only available between $49^{\circ} \mathrm{S}$ and $49^{\circ} \mathrm{N}$. Given that CAM5 has replaced the CAM4 parameterizations for almost all the model physical processes except for deep convection, it is somewhat surprising to see how similar biases are in CAM4- and CAM5-produced mean tropical precipitation fields in their AMIP runs in the tropical and subtropical regions. This suggests the dominant role that model deep convection parameterization plays in controlling the simulation of tropical precipitation. The most prominent errors shown in these 
two versions of CAM are the excessive precipitation over much of the tropics, including over the tropical Africa, the oceans adjacent to the Indian peninsula, the Tibetan Plateau, the central and eastern Pacific, the vicinity of Central America, and the Andes mountain range along the Pacific coast of South America. Precipitation deficits are seen over a broad stretch of the Indian Ocean, Maritime Continent, and western Pacific although the problem is slightly alleviated in CAM5. Both models also underestimate precipitation over central South America with larger errors shown in CAM5. In general, biases over tropical lands are larger in boreal winter. These biases are not uncommon to many climate models (Lin 2007). The unrealistic doubleITCZ pattern in the simulated tropical precipitation marked by excessive precipitation off the equator in the central and eastern Pacific is evident in both the CAM4 and CAM5 AMIP runs. This error is larger in boreal spring and becomes more severe when the atmospheric model is coupled with an ocean in which the oceanatmosphere feedback is involved.

Despite being less strong, most of the climate errors are remarkably similar in their hindcasts. These include those regions where the models produce excessive precipitation and the central South American region where all models show deficits of precipitation. These errors show similar seasonal variations to those exhibited in the AMIP runs. Therefore, the correspondence between short- and long-term simulations seen in the annualmean data remains similar throughout the seasonal cycle. It is worth noting that some long-standing climate errors such as the deficits of precipitation in the joint area of the Indian Ocean, Maritime Continent, and western Pacific are not clearly shown in the day 2 hindcasts in both models while they are apparent in their day 5 hindcasts, indicating that the bias is likely a result of some kind of feedbacks between different dynamical and physical processes that take a longer time to impact model precipitation simulations. Using a similar weather forecast approach, Strachan et al. (2006) have investigated the physics-dynamics interactions in the growth of the dry bias over the Maritime Continent exhibited in the Hadley Center Global Atmosphere Model version 1 (HadGAM1). They hypothesized that the precipitation deficit over the region is a response to enhanced convective activity over surrounding oceanic regions. Anomalous ascent over the western Indian Ocean and western Pacific Ocean leads to anomalous descent and hence drying over the Maritime Continent. Also noticed is that the double-ITCZ problem and the excessive precipitation over the oceans adjacent to northwest Australia in the AMIP runs are not present or clear in the hindcasts, suggesting errors may need even longer time to
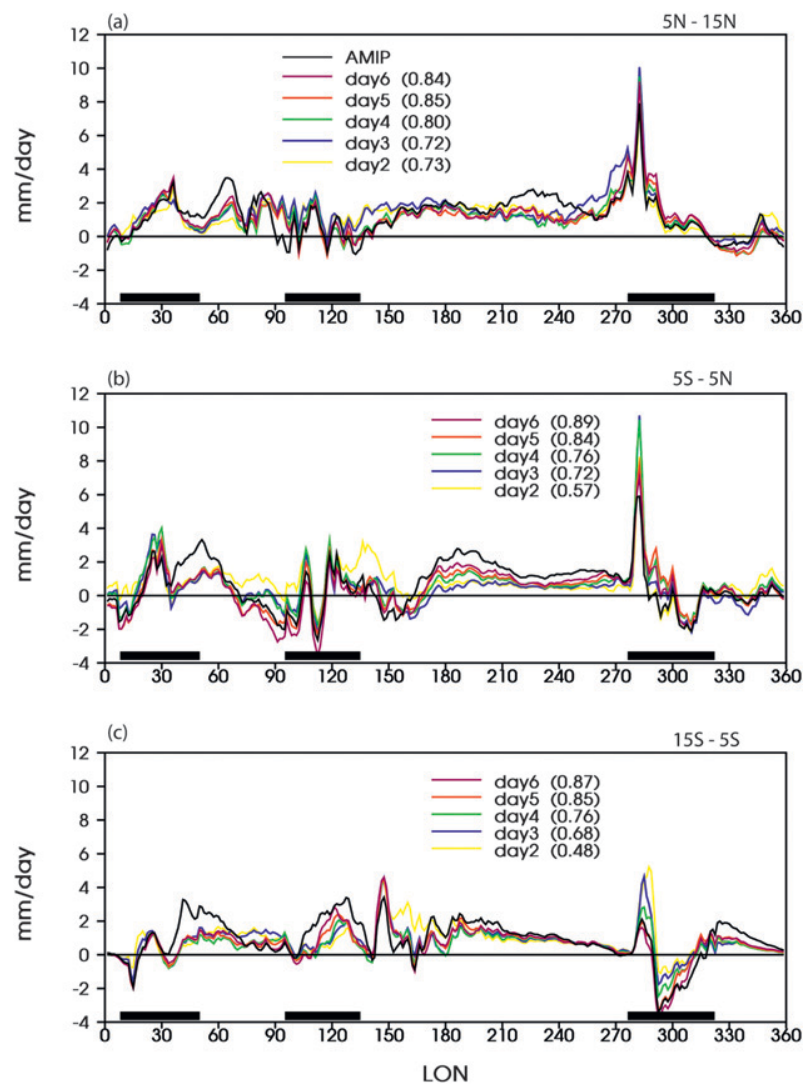

FIG. 6. Difference in the annual-mean precipitation between CAM 5 and TRMM averaged over (a) $5^{\circ}-15^{\circ} \mathrm{N}$, (b) $5^{\circ} \mathrm{S}-5^{\circ} \mathrm{N}$, and (c) $15^{\circ}-5^{\circ} \mathrm{S}$ for its AMIP run and day $2-6$ hindcasts. Locations of tropical lands are marked as thick black lines on the $x$ axis. The numbers within parentheses are the correlation coefficients between climate errors and hindcast errors.

fully develop. This suggests that both the similarity and difference could provide an opportunity to improve our understanding of these errors through performing an indepth analysis of these short-term hindcasts, such as examining how these errors grow with hindcast lead time and what feedback or interaction between different processes may be involved in error development.

To further analyze the tropical precipitation errors, Figs. $6 a-c$ show the zonal profiles of annual-mean precipitation errors in CAM 5 averaged over $5^{\circ}-15^{\circ} \mathrm{N}$, $5^{\circ} \mathrm{S}-5^{\circ} \mathrm{N}$, and $15^{\circ}-5^{\circ} \mathrm{S}$, respectively. The numbers within parentheses are the correlation coefficients between climate errors and hindcast errors. Consistent with what has been shown earlier, the model produces excessive precipitation over much of the tropics. Insufficient precipitation simulated by the model is seen over the Indian Ocean and Maritime Continent near the equator and over Central and South America (Fig. 6b). The correlation between climate errors and hindcast errors increases steadily with hindcast lead time and seems to saturate in day 5 hindcasts. 

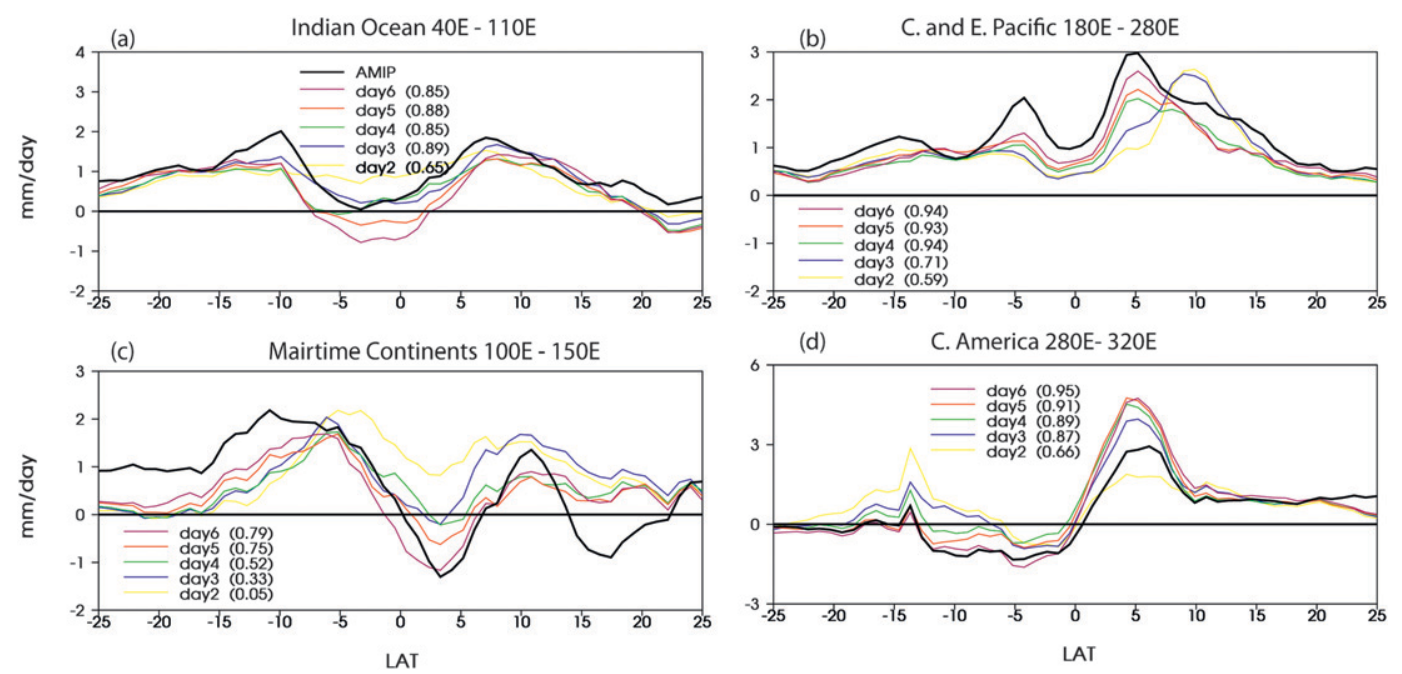

FIG. 7. Difference in the annual-mean precipitation between CAM5 and TRMM averaged over the (a) Indian Ocean $\left(40^{\circ}-110^{\circ} \mathrm{E}\right)$, (b) central and eastern Pacific $\left(180^{\circ}-280^{\circ} \mathrm{E}\right)$, (c) Maritime Continent $\left(100^{\circ}-150^{\circ} \mathrm{E}\right)$, and (d) Central America $\left(280^{\circ}-320^{\circ} \mathrm{E}\right)$ for its AMIP run and day 2-6 hindcasts. The numbers within parentheses are the correlation coefficients between climate errors and hindcast errors.

Precipitation errors are typically larger and show stronger variability over the tropical lands (marked by the dark black lines on the $x$ axis) and the adjacent ocean regions than the open tropical oceans. This indicates that this model has more problems in capturing convection over land than over ocean. It is interesting to see that errors over tropical lands in the hindcasts are usually larger than the climate simulation, indicating that the model deficiency is amplified in the hindcasts, which allows us to use more extensive observations including field data to understand the cause of the errors.

Figures $7 \mathrm{a}-\mathrm{d}$ display the zonal annual-mean precipitation errors in CAM5 over the Indian Ocean $\left(40^{\circ}-110^{\circ} \mathrm{E}\right)$, central and eastern Pacific $\left(180^{\circ}-280^{\circ} \mathrm{E}\right)$, Maritime Continent $\left(100^{\circ}-150^{\circ} \mathrm{E}\right)$, and Central America $\left(280^{\circ}-\right.$ $320^{\circ} \mathrm{E}$ ), respectively. The evolution of tropical precipitation hindcast bias gradually toward its climate bias is also clearly shown in the meridional profiles. Over the central and eastern Pacific and Central America, the correlation between the hindcasts and the AMIP runs is very strong. Precipitation errors are small along the equator and large between $5^{\circ}$ and $10^{\circ}$ off the equator in both hemispheres. The double-ITCZ feature is much clearer in the AMIP run than for the hindcast runs over the central and eastern Pacific (Fig. 7b).

Figure 8 shows the difference in the annual-mean total cloud amount between the models and the CALIPSO satellite observations for different types of model runs. The model clouds are diagnosed by using the CALIPSO simulator with cloud physical properties specified from the corresponding models. In the tropical and subtropical regions, for the AMIP runs, both CAM4 and
CAM5 overestimate the observed total cloud amount (mainly high clouds) over the regions where they produce excessive precipitation, while they both underestimate the cloud on the downwind edges of the stratocumulus cloud decks where stratocumulus break up into trade cumulus over the eastern subtropical oceans. In comparison with CAM4, there is a significant increase of high and low clouds and a moderate increase of midlevel clouds in CAM5 (not shown). This is consistent with Kay et al. (2012), who documented cloud errors using CALIPSO and other simulators in 10-yr integrations of CAM4 and CAM5. As a result, CAM5 further amplifies the problem of overestimating high clouds, but it considerably improves the simulation of low and midlevel clouds. The lack of midlevel clouds has been found in several generations of CAM and many other models (Zhang et al. 2005). Figures 8c-f display very similar biases in short-range hindcasts for both models, indicating that systematic errors in both climate simulations and weather hindcasts could be due to the same deficiencies in representing clouds in these models.

Consistent with the biases shown in the precipitation and cloud fields, both CAM4 and CAM5 display an underestimate of outgoing longwave radiation (OLR) (Fig. 9) corresponding to an overestimate of precipitation, and vice versa, in the tropical and subtropical regions. However, this correspondence is not clear over the regions where precipitation errors are small, which suggests that errors in other fields such as in temperature and water vapor might have impacted the OLR simulation. In comparison to CAM4, CAM5 has made considerable improvement in the simulation of OLR in the 

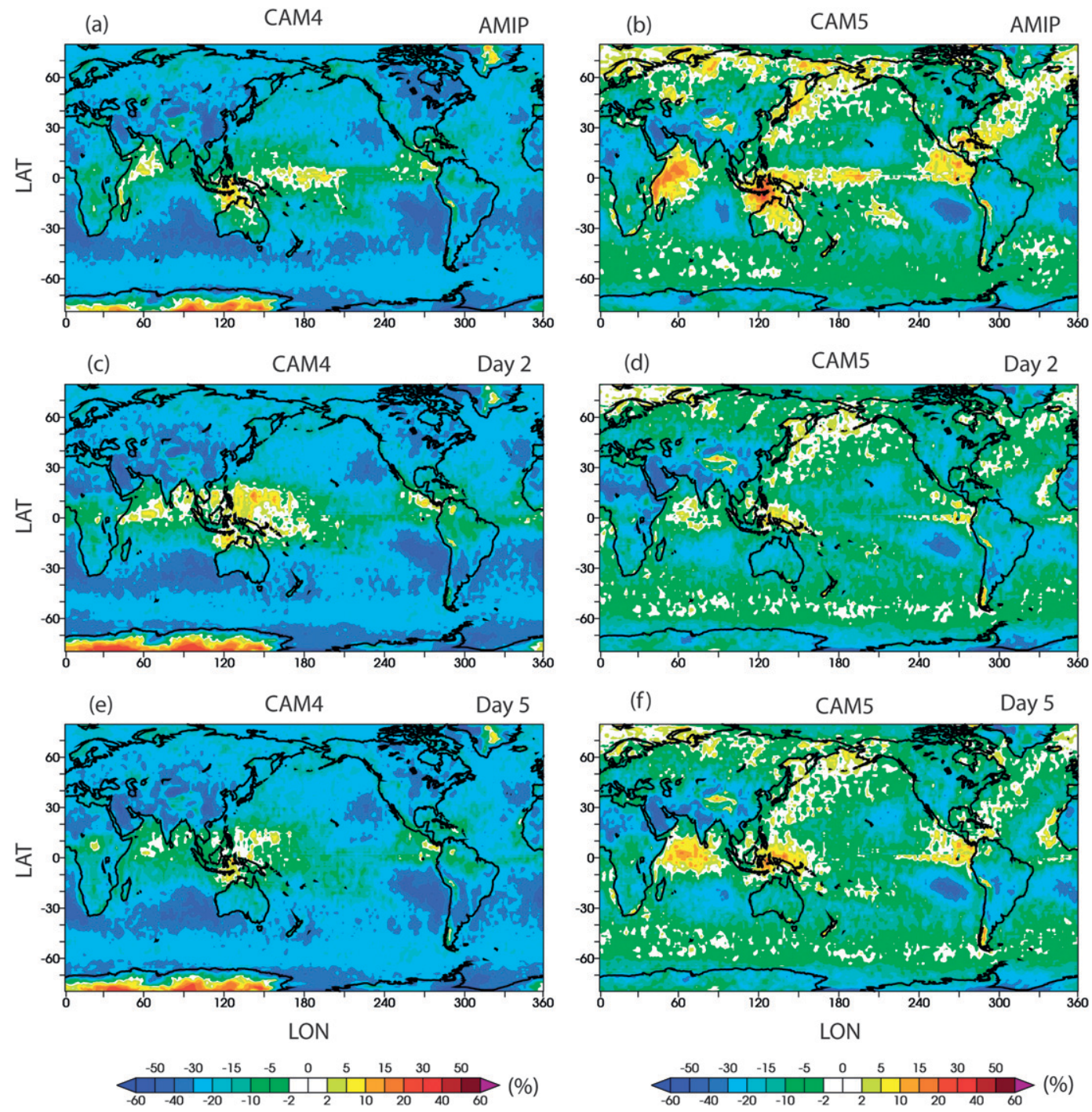

FIG. 8. Global distribution of the difference in the annual-mean total cloud amount between different types of model runs and the CALIPSO observations for the year 2009: (a) CAM4 AMIP run, (b) CAM5 AMIP run, (c) CAM4 day 2 hindcasts, (d) CAM5 day 2 hindcasts, (e) CAM4 day 5 hindcasts, and (f) CAM5 day 5 hindcasts.

subtropical and midlatitude storm track regions in both hemispheres. It is noted that the correspondence between hindcast errors and climate errors in OLR is not as strong as that shown in the precipitation and cloud fields, especially in the high latitudes. In addition, the problem of excessive OLR in the midlatitudes is exaggerated in the hindcasts.

Figure 10 is as in Fig. 9 but for the annual-mean shortwave absorbed radiation (SWAbs). A typical problem in SWAbs with many climate models is the overestimation of SWAbs in the coastal zones of the eastern subtropical oceans due to the underestimation of stratocumulus (Trenberth and Fasullo 2010). This error is also present in the CAM models with a noticeable reduction seen in CAM5 compared to CAM4, consistent with the improvement of simulating stratocumulus in CAM5. Over the tropical deep convective regions, particularly over land, both models underestimate SWAbs due to an overestimation of precipitation and clouds. The hindcast runs produce an almost identical error pattern to that shown in the AMIP runs, suggesting the strong correlation and quick feedback between clouds and SWAbs.

\section{c. Beyond the tropics}

We have demonstrated the strong correspondence between short and long time-scale systematic errors in CAM4 and CAM5 in the tropics. This correspondence is 

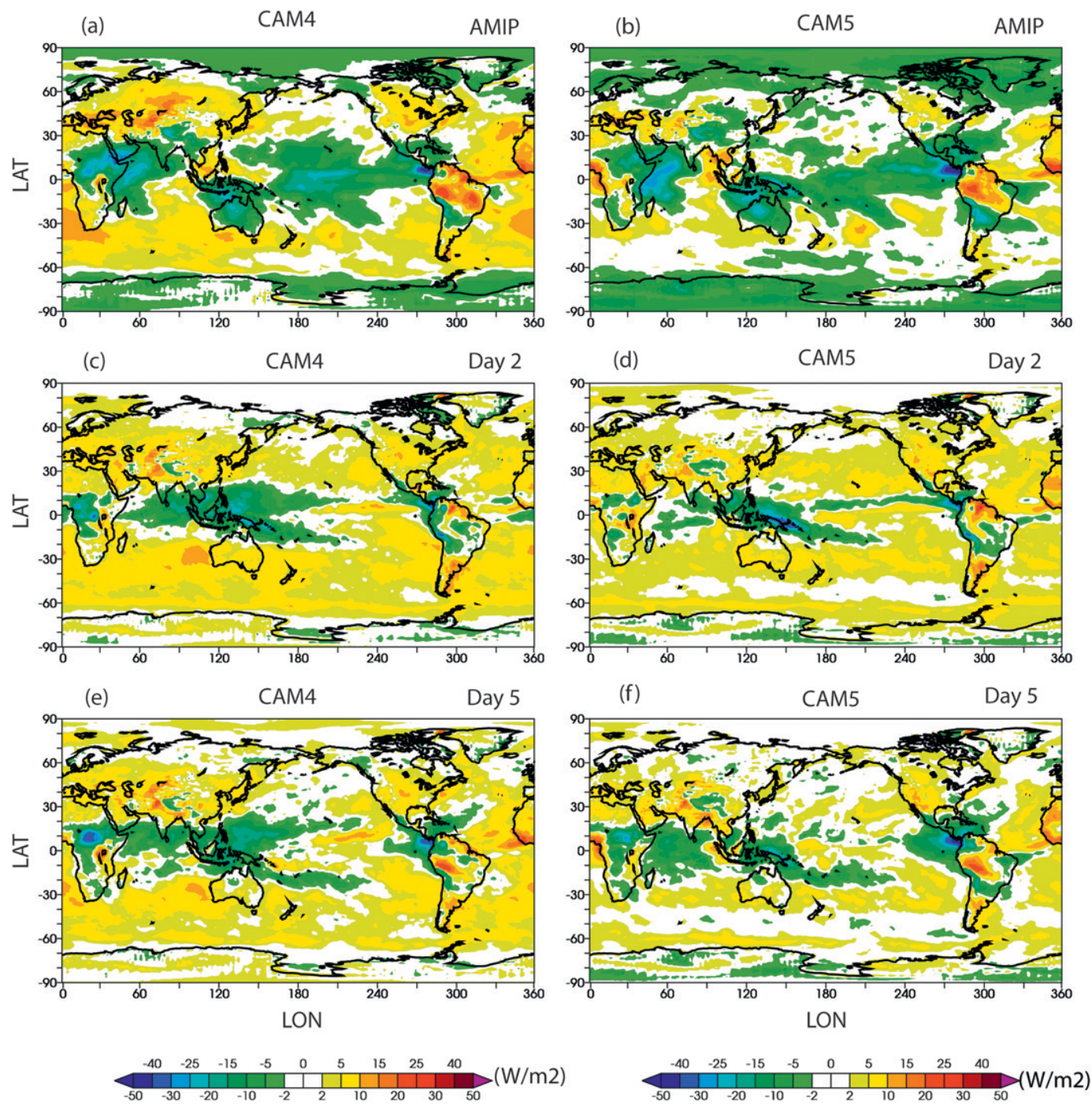

FIG. 9. Global distribution of the difference in the annual-mean OLR between different types of model runs and the CERES observations for the year 2009: (a) CAM4 AMIP run, (b) CAM5 AMIP run, (c) CAM4 day 2 hindcasts, (d) CAM5 day 2 hindcasts, (e) CAM4 day 5 hindcasts, and (f) CAM5 day 5 hindcasts.

also apparent in the midlatitude and high-latitude regions even though diabatic processes are somewhat less dominant in the extratropics compared to the tropics. Examples include the prominent overestimate of SWAbs in the open-ocean areas adjacent to the sea ice margin at nearly all longitudes of the Southern Ocean at about $30^{\circ}-60^{\circ} \mathrm{S}$ (Fig. 10). This is a very common error in CMIP3 models (Trenberth and Fasullo 2010). It is noticed that the error in CAM5 is considerably smaller than in CAM4 at $30^{\circ}-50^{\circ} \mathrm{S}$. The reduction of SWAbs in CAM5 is associated with its increase in total cloud amount, particularly in mid and low level clouds, over that region (Fig. 8) compared to CAM4. The overestimation of clouds along the midlatitude storm track in the CAM5 AMIP runs is also evident in its hindcasts. It is interesting to see that the SWAbs field shows quite a large difference between CAM4 and CAM5 and between the CAM5 AMIP run and its hindcasts in the polar region where the CAM5 AMIP run overestimates SWAbs, while both the CAM4 AMIP and hindcast runs and the CAM5 hindcast runs underestimate SWAbs.

Other examples include the surface air temperature $\left(T_{s}\right)$ for which the short-range hindcasts and long-term AMIP runs produce almost identical errors globally (Fig. 11), such as the significant warm biases over lowand midlatitude lands and cold biases in the polar region in comparison with the ECMWF analysis. The warm biases are likely related to the underestimation of clouds 

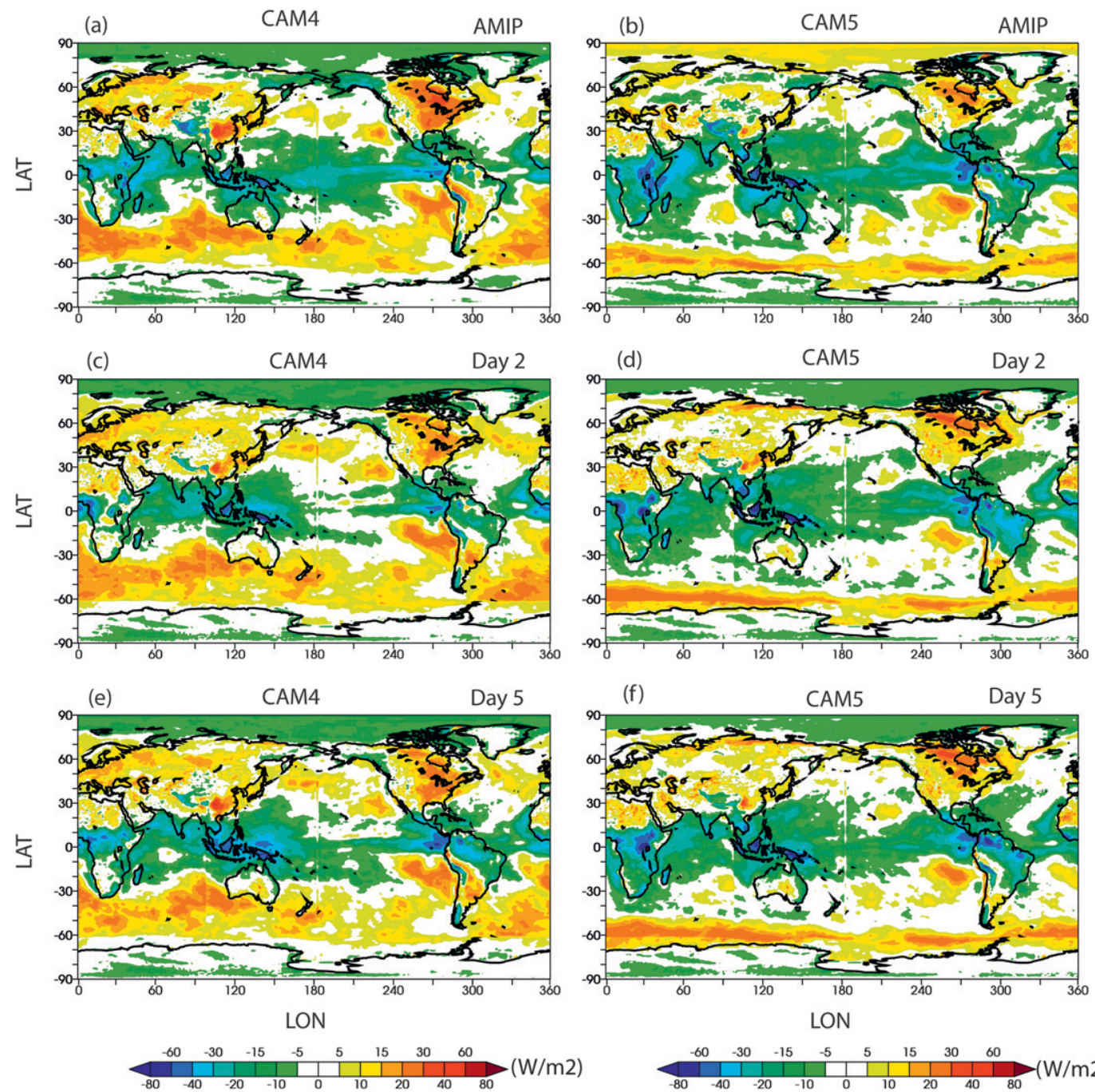

FIG. 10. As in Fig. 9, but for SWAbs.

over these regions, as discussed earlier. Similar correspondence can also be found in the sea level pressure (SLP) simulated by these models. As shown in Fig. 12, the most prominent error is an annular-mode bias with higher SLP along midlatitude storm tracks in both hemispheres displayed in both climate and hindcast runs in comparison with the ECMWF analysis, although the biases are significantly smaller in their day 2 hindcasts, suggesting that this model problem needs time to develop. Compared to higher latitudes, the errors are much smaller in tropical and subtropical regions. Similar to SWAbs, quite significant differences are seen between CAM4 and CAM5 and between the CAM5 AMIP run and its hindcasts in the high-latitude region of the Northern Hemisphere. The negative bias shown in CAM4 is replaced by generally positive bias in CAM5. Although CAM5 hindcasts also show positive bias in this region as its climate run does, there is significant difference in the location where maximum errors occur between these two types of runs. These differences may reflect quite significant differences in the general circulation over the polar region between CAM4 and CAM5 as well as between CAM5 climate and CAM5 hindcasts. It should be noted that the systematic errors in SLP and SWAbs shown in the CAM5 AMIP run, including those in the polar region, are very similar to those shown in its 20-yr AMIP runs as seen on the CESM webpage (http:// www.cesm.ucar.edu/experiments/cesm1.0/).

Figures 13 and 14 are Taylor diagrams (Taylor 2001) that summarize the pattern statistics [both spatial correlations and standard deviations (STDs)] between hindcast errors (the day 2-6 hindcasts) and climate errors (the AMIP runs) for selected fields over the tropical and subtropical region (i.e., $35^{\circ} \mathrm{S}-35^{\circ} \mathrm{N}$ ), midlatitudes 

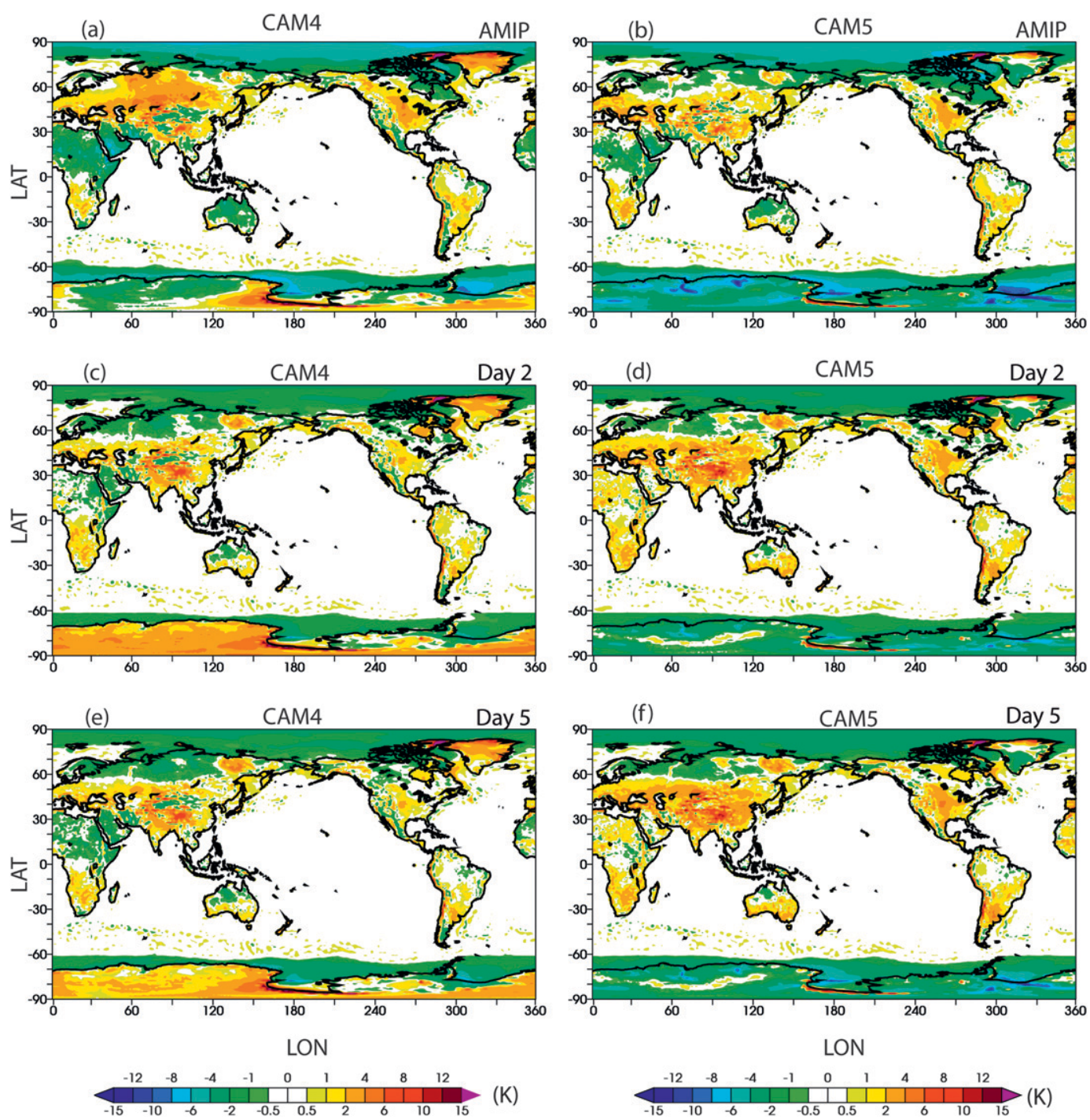

FIG. 11. Global distribution of the difference in the annual-mean surface temperature between types of model runs and the ECMWF analysis for the year 2009: (a) CAM4 AMIP run, (b) CAM5 AMIP run, (c) CAM4 day 2 hindcasts, (d) CAM5 day 2 hindcasts, (e) CAM4 day 5 hindcasts, and (f) CAM5 day 5 hindcasts.

$\left(35^{\circ}-65^{\circ} \mathrm{N} / \mathrm{S}\right)$, and high latitudes $\left(65^{\circ}-90^{\circ} \mathrm{N} / \mathrm{S}\right)$ for CAM4 and CAM5, respectively. In the Taylor diagram the radial distances from the original to the points are proportional to the pattern STDs, and the azimuthal positions give the correlation coefficient between the two patterns. Note that the correlation is not linear with angle. The distance between a simulated field and the reference data is proportional to their centered rms error (RMSE). The selected fields include surface precipitation, OLR, SWAbs, SLP, and $T_{s}$.

Consistent with earlier discussions, there is a strong correspondence between hindcast errors and climate errors for these selected fields. Most fields have an error pattern correlation larger than 0.6 over the examined regions between these two types of runs. The hindcast errors in both correlations and standard deviations typically gradually evolve with time toward the AMIP errors, but they do not reach the AMIP errors, even in day 6. This indicates that a 6-day hindcast is apparently not long enough. Among these selected fields, the pattern correlations between climate errors and hindcast errors for SLP and OLR are relatively weak. In the Northern Hemisphere extratropics (Figs. 14b,d) there is almost no pattern correlation in SLP between its hindcast errors and its climate errors for CAM5. The error pattern correlation is also weak with the coefficient around 0.2 for SWAbs in the Arctic region for CAM5 (Fig. 14d) due to the opposite error pattern 

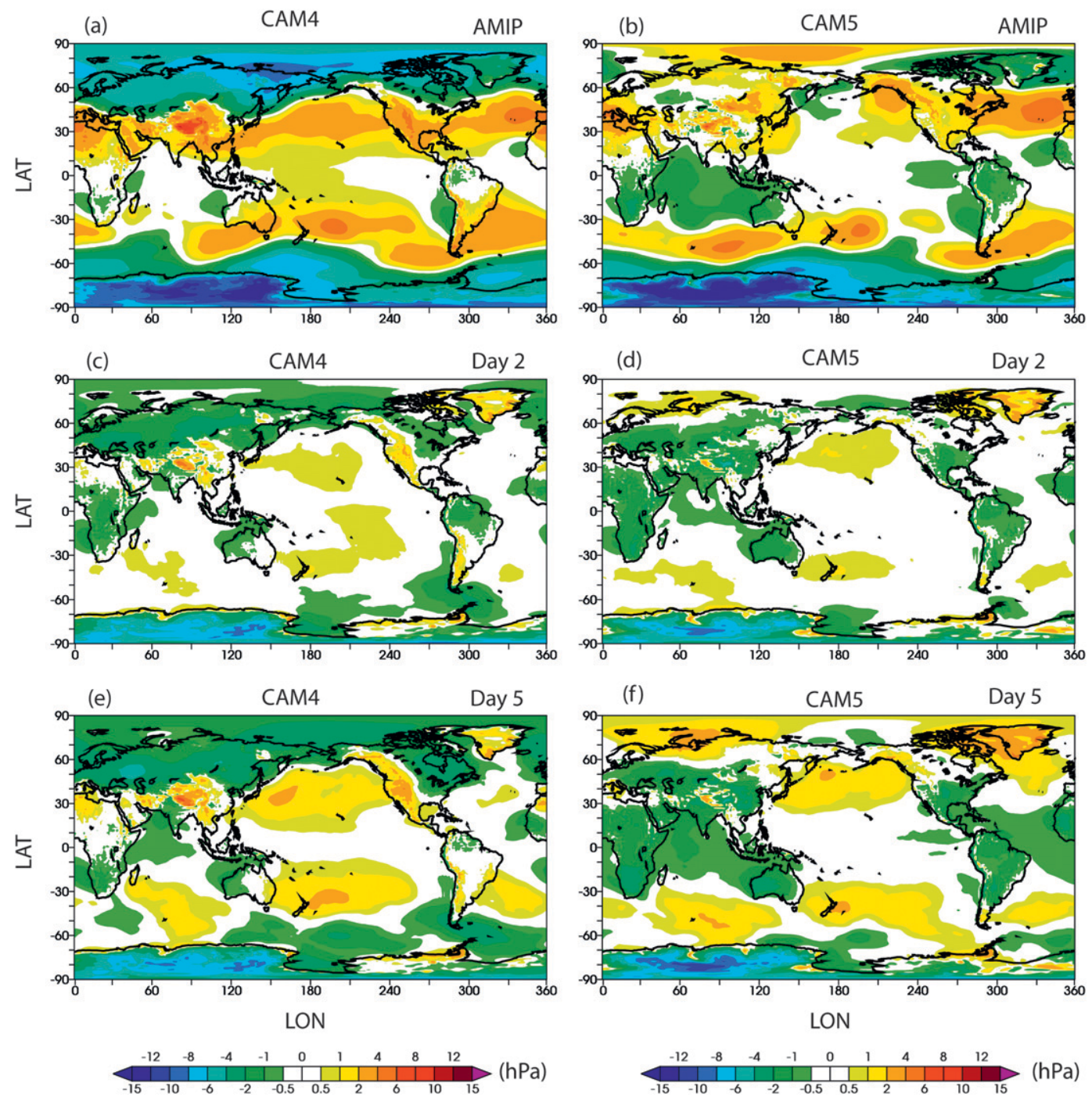

FIG. 12. As in Fig. 11, but for SLP.

exhibited in its hindcasts and AMIP runs, as shown in Fig. 10.

It is interesting to see that errors in these selected fields typically show a smaller spatial standard deviation in the hindcasts than the AMIP runs, suggesting a smaller spatial variability and also a smaller magnitude in the hindcast errors over these regions. Among these variables, SLP has the smallest standard deviation. Also note that the evolution of hindcast errors for most of the fields is much clearer in the tropical and subtropical regions than in higher latitude regions, indicating that a longer time scale is required for these systematic errors to saturate in the tropics and subtropics. In general, the errors that are closely associated with cloud biases (i.e., SWAbs and $T_{s}$ ) develop faster (usually apparent at day 2 hindcasts) than those that are not (i.e., SLP) for all the regions.

\section{Summary and future work}

We have systematically documented the correspondence between short and long time-scale systematic errors in CAM4 and CAM5 using data from a series of 6-day hindcasts with the two models initialized at 0000 UTC every day from the ECMWF analysis and the 3-yr "free running" AMIP simulations for the YOTC period. Our focus is on those well-known climate biases that are exhibited in both CAM models and many other climate models. The analysis is based on annual-mean errors, which were constructed from the composite of day 2 to day 6 hindcasts and the AMIP simulations for the complete year of 2009 within the YOTC period.

We have examined systematic errors in the modelproduced tropical general circulation and those moistprocess-related fields like surface precipitation, clouds, 


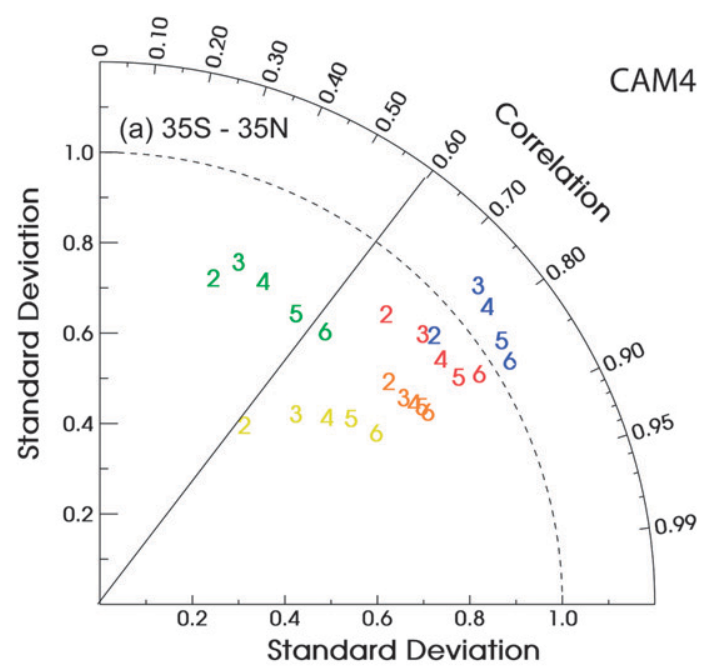

ANN Precipitation

ANN OLR

ANN SWAbs

ANN SLP

ANN TS

2:CAM4-Day2

3:CAM4-Day3

4:CAM4-Day4

5:CAM4-Day5

6:CAM4-Day6
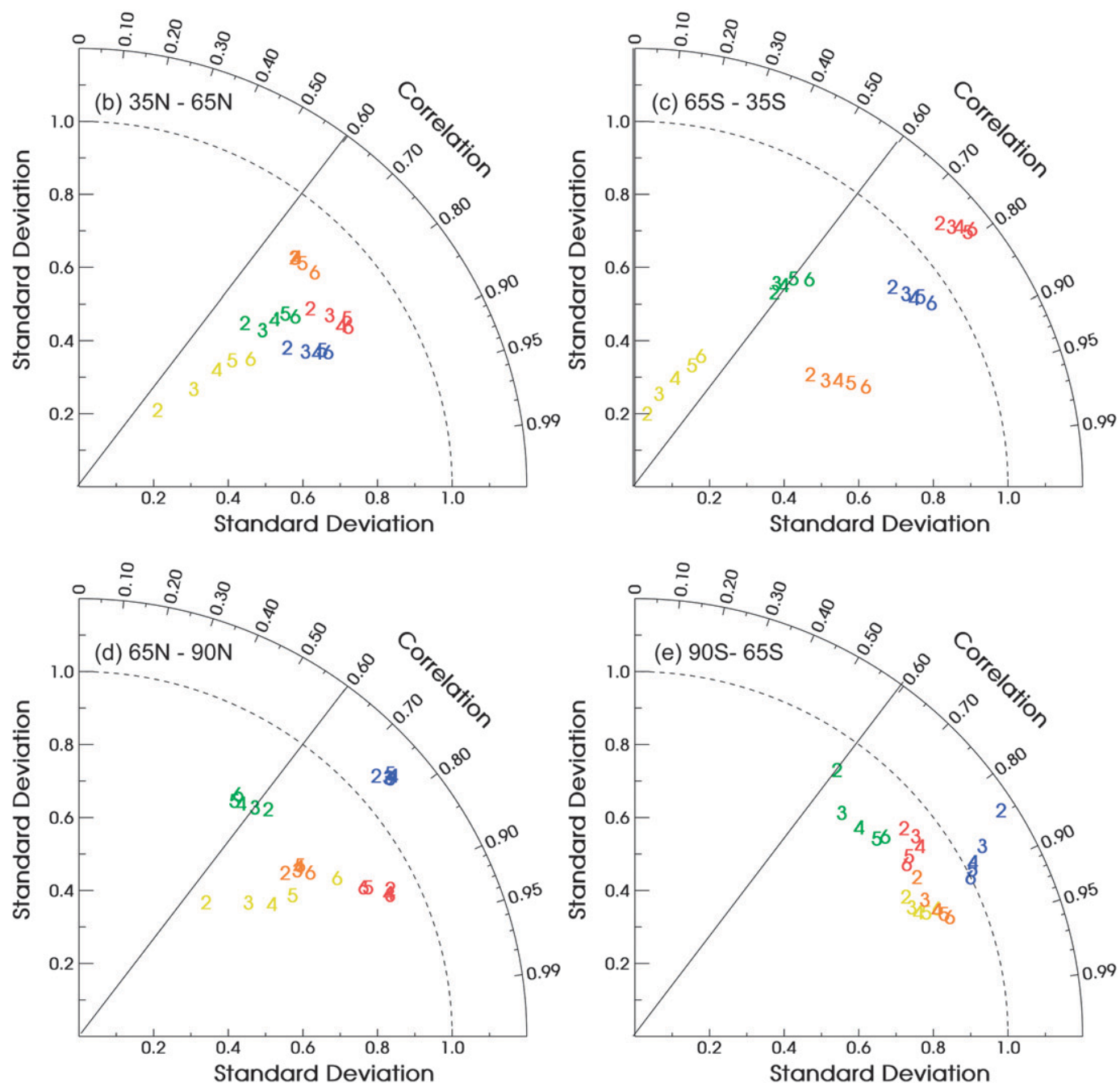

FIG. 13. Taylor diagrams that summarize the pattern statistics between the CAM4 hindcast errors (the day 2-6 hindcasts) and its climate errors (the AMIP runs) for annual-mean surface precipitation, OLR, SWAbs, LWCF, SWCF, SLP, $T_{s}$, and CWV over (a) the tropical and subtropical regions $\left(35^{\circ} \mathrm{S}-35^{\circ} \mathrm{N}\right)$, (b) midlatitudes in the Northern Hemisphere $\left(35^{\circ}-65^{\circ} \mathrm{N}\right)$, (c) midlatitudes in the Southern Hemisphere $\left(35^{\circ}-65^{\circ} \mathrm{S}\right)$, (d) high latitudes in the Northern Hemisphere $\left(65^{\circ}-90^{\circ} \mathrm{N}\right)$, and (e) high latitudes in the Southern Hemisphere $\left(65^{\circ}-90^{\circ} \mathrm{S}\right)$. 


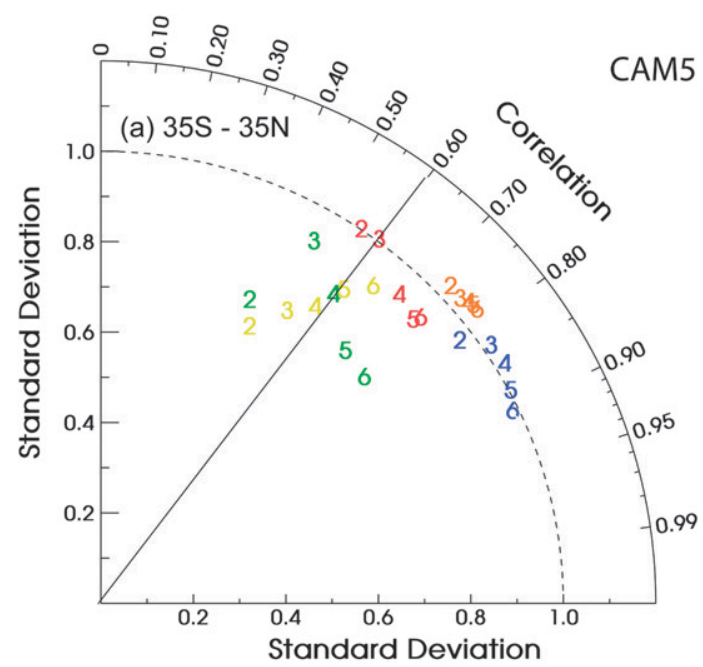

ANN Precipitation

ANN OLR

ANN SWAbs

ANN SLP

ANN TS

2:CAM4-Day2

3:CAM4-Day3

4:CAM4-Day4

5:CAM4-Day5

6:CAM4-Day6
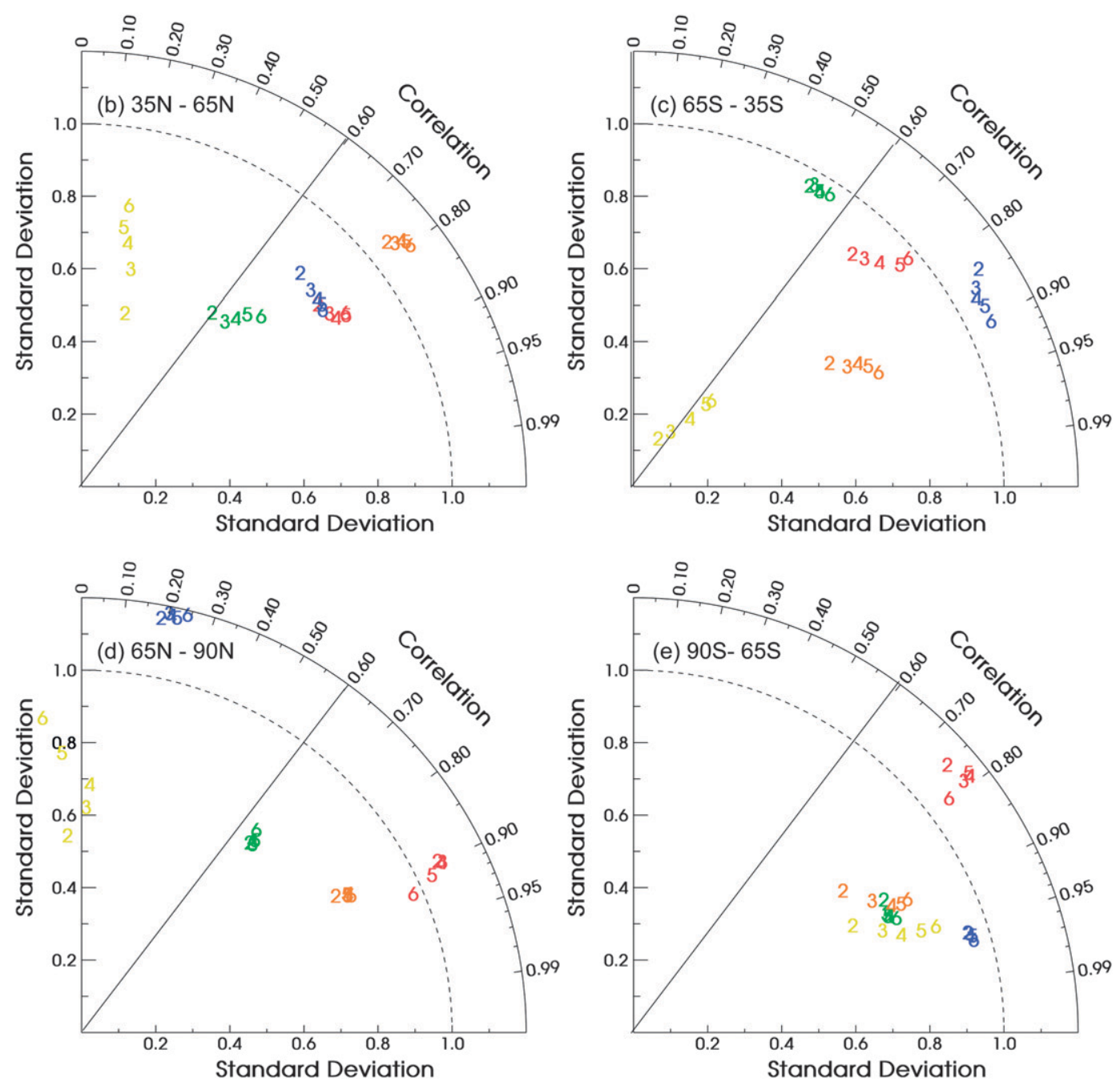

FIG. 14. As in Fig. 13, but for CAM5. 
and radiation. Errors in the surface temperature and sea level pressure are also discussed. It has been shown that a strong correlation exists between hindcast errors and climate errors in CAM4 and CAM5. Some of the errors develop fast and apparent in just the day 2 hindcasts, such as the biases in the tropical troposphere temperature and water vapor, the excessive precipitation over much of the tropics, the underestimation of stratocumulus cloud decks over the eastern subtropical oceans, the overestimation of net shortwave absorbed radiation in the Southern Ocean at about $60^{\circ} \mathrm{S}$, and the warm biases in surface air temperature over low-latitude and midlatitude lands. This may suggest that these errors are likely the result of model parameterization errors as the large-scale flow remains close to observed in the first few days hindcasts. In contrast, other climate errors are present in the hindcasts, but with amplitudes that are significantly smaller and do not gradually approach their climate errors. These include the prominent cold biases near the tropical tropopause and in the lower stratosphere and the unrealistic double-intertropical convergence zone pattern shown in simulated tropical precipitation. This indicates that these biases could be related to slower processes such as radiative and chemical processes that have important impact in the lower stratosphere or the result of various feedbacks between dynamical and physical processes that take longer time to impact model simulations (i.e., the doubleITCZ problem). It is also found that some long-standing climate errors such as the deficits of precipitation near the Maritime Continent are not shown in the day 2 hindcasts, while they are apparent in the day 5 hindcasts, suggesting that feedbacks between dynamical and physical processes need to be involved for these errors to develop. Among these examined fields, the pattern correlation between hindcast errors and climate errors is relatively weak for sea level pressure and outgoing longwave radiation since many processes could impact their simulations.

The correspondence between the short and long timescale errors remains strong throughout the seasonal cycle. This strong connection between hindcasts and climate simulations allows us to perform in-depth analyses of these climate errors by using the weather hindcast approach with more available observations and highfrequency NWP analyses. We have started to apply those standard metrics that are commonly used to systematically assess climate model performance skill (Gleckler et al. 2008) to the hindcast runs with emphasis given to those climate-relevant quantities such as radiation, clouds, and precipitation (Ma et al. 2012). We plan to develop diagnostics specifically for these long-lasting model errors, such as the unrealistic double-ITCZ precipitation pattern and other major tropical precipitation biases, to gain insights into these model errors. Sensitivity tests with different physical parameterizations and process studies with field campaign data will be done to identify what physical process is most responsible for these errors. The hypotheses proposed in earlier studies on these well-known climate biases could be also tested using the framework set up by this study. It should be noted that the findings from this study are based on only 1-yr hindcast data during the YOTC period. A decadal-long series of CAM4/CAM5 is currently planned to examine if these model biases are statistically significant and our findings in this study are robust.

Acknowledgments. This work is supported by the Regional and Global Climate Modeling Program and Atmospheric System Research Program of the Office of Science at the U.S. Department of Energy. Work at LLNL was performed under the auspices of the U.S. Department of Energy, Office of Science, Office of Biological and Environmental Research by Lawrence Livermore National Laboratory under Contract DE-AC52-07NA27344.

\section{REFERENCES}

Bodas-Salcedo, A., and Coauthors, 2011: COSP: Satellite simulation software for model assessment. Bull. Amer. Meteor. Soc., 92, 1023-1043.

Boville, B. A., P. J. Rasch, J. J. Hack, and J. R. McCaa, 2006: Representation of clouds and precipitation processes in the Community Atmosphere Model Version 3 (CAM3). J. Climate, 19, 2184-2198.

Boyle, J. S., and Coauthors, 2005: Diagnosis of Community Atmospheric Model 2 (CAM2) in numerical weather forecast configuration at Atmospheric Radiation Measurement sites. J. Geophys. Res., 110, D15S15, doi:10.1029/2004JD005042.

_ - S. Klein, G. Zhang, S. Xie, R. Pincus, and X. Wei, 2008: Climate model forecast experiments for TOGA COARE. Mon. Wea. Rev., 136, 808-832.

Bretherton, C. S., and S. Park, 2009: A new moist turbulence parameterization in the Community Atmosphere Model. J. Climate, 22, 3422-3448.

Gates, W. L., and Coauthors, 1999: An overview of the results of the Atmospheric Model Intercomparison Project (AMIP I). Bull. Amer. Meteor. Soc., 80, 29-55.

Gleckler, P. J., K. E. Taylor, and C. Doutriaux, 2008: Performance metrics for climate models. J. Geophys. Res., 113, D06104, doi:10.1029/2007JD008972.

Hack, J. J., J. T. Kiehl, and J. W. Hurrell, 1998: The hydrologic and thermodynamic characteristics of the NCAR CCM3. J. Climate, 11, 1179-1206.

Hamilton, K., R. J. Wilson, J. D. Mohlman, and L. J. Umscheid, 1995: Climatology of the SKYHI troposphere-stratospheremesosphere general circulation model. J. Atmos. Sci., 52, 5-43.

Iacono, M. J., E. J. Mlawer, S. A. Clough, and J.-J. Morcrette, 2000: Impact of an improved longwave radiation model, RRTM, on the energy budget and thermodynamic properties 
of the NCAR community climate model, CCM3.J. Geophys. Res., 105, 14 873-14 890.

Kay, J. E., and Coauthors, 2012: Exposing global cloud biases in the Community Atmosphere Model (CAM) using satellite observations and their corresponding instrument simulators. J. Climate, 25, 5190-5207.

Klein, S. A., X. Jiang, J. Boyle, S. Malyshev, and S. Xie, 2006: Diagnosis of the summertime warm and dry bias over the U.S. Southern Great Plains in the GFDL climate model using a weather forecasting approach. Geophys. Res. Lett., 33, L18805, doi:10.1029/2006GL027567.

Lin, J. L., 2007: The double-ITCZ problem in IPCC AR4 coupled GCMs: Ocean-atmosphere feedback analysis. J. Climate, 20, 4497-4525.

Liu, X., and Coauthors, 2012: Toward a minimal representation of aerosols in climate models: Description and evaluation in the Community Atmosphere Model CAM5. Geosci. Model Dev., 5, 709-739.

Ma, H.-Y., S. Xie, J. S. Boyle, S. A. Klein, and Y. Zhang, 2012: Metrics and diagnostics for precipitation-related processes in climate model short-range forecasts. J. Climate, in press.

Martin, G. M., S. F. Milton, C. A. Senior, M. E. Brooks, and S. Ineson, 2010: Analysis and reduction of systematic errors through a seamless approach to modeling weather and climate. J. Climate, 23, 5933-5957.

Mlawer, E. J., S. J. Taubman, P. D. Brown, M. J. Iacono, and S. A. Clough, 1997: Radiative transfer for inhomogeneous atmospheres: RRTM, a validated correlated-k model for the longwave. J. Geophys. Res., 102, 16 663-16 682.

Moncrieff, M. W., D. E. Waliser, M. J. Miller, M. A. Shapiro, G. R Asrar, and J. Caughey, 2012: Multiscale convective organization and the YOTC virtual global field campaign. Bull. Amer. Meteor. Soc., 93, 1171-1187.

Morrison, H., and A. Gettelman, 2008: A new two-moment bulk stratiform cloud microphysics scheme in the NCAR Community Atmosphere Model (CAM3). Part I: Description and numerical tests. J. Climate, 21, 3642-3659.

Neale, R. B., J. H. Richter, and M. Jochum, 2008: The impact of convection on ENSO: From a delayed oscillator to a series of events. J. Climate, 21, 5904-5924.

- , and Coauthors, 2010: Description of the NCAR Community Atmosphere Model (CAM 5.0). NCAR Tech. Note NCAR/ TN-486+STR, 268 pp. [Available online at http://www.cesm. ucar.edu/models/cesm1.0/cam/docs/description/cam5_desc.pdf.]

Park, S., and C. S. Bretherton, 2009: The University of Washington shallow convection and moist turbulence schemes and their impact on climate simulations with the Community Atmosphere Model. J. Climate, 22, 3449-3469.

Phillips, T. J., and Coauthors, 2004: Evaluating parameterizations in general circulation models: Climate simulation meets weather prediction. Bull. Amer. Meteor. Soc., 85, 1903-1915.

Randall, D. A., and Coauthors, 2007: Climate models and their evaluation. Climate Change 2007: The Physical Science
Basis, S. Solomon et al., Eds., Cambridge University Press, 589-662.

Rodwell, M. J., and T. N. Palmer, 2007: Using numerical weather prediction to assess climate models. Quart. J. Roy. Meteor. Soc., 133, 129-146.

Simpson, J., R. F. Adler, and G. R. North, 1988: A proposed Tropical Rainfall Measuring Mission (TRMM). Bull. Amer. Meteor. Soc., 69, 278-295.

Strachan, J., P. M. Inness, J. M. Slingo, and G. M. Martin, 2006: Running a climate model in forecast mode to identify the source of tropical climate errors: With specific reference to the dry bias error over the Maritime Continent in an atmosphere only GCM. Preprints, 18th Conf. on Climate Variability and Change, Atlanta, GA, Amer. Meteor. Soc., 91. [Available online at https://ams.confex.com/ams/pdfpapers/101221.pdf.]

Taylor, K. E., 2001: Summarizing multiple aspects of model performance in a single diagram. J. Geophys. Res., 106, 7183-7192.

Trenberth, K. E., and J. T. Fasullo, 2010: Simulation of present-day and twenty-first- and century energy budgets of the southern oceans. J. Climate, 23, 440-454.

Waliser, D. E., and Coauthors, 2012: The "Year" of Tropical Convection (May 2008-April 2010): Climate variability and weather highlights. Bull. Amer. Meteor. Soc., 93, 1189-1218.

Wielicki, B. A., B. R. Barkstorm, E. F. Harrison, R. B. Lee III, G. L. Smith, and J. E. Cooper, 1996: Clouds and the Earth's Radiant Energy System (CERES): An Earth Observing System experiment. Bull. Amer. Meteor. Soc., 77, 853-868.

Williams, K. D., and M. E. Brooks, 2008: Initial tendencies of cloud regimes in the Met Office Unified Model. J. Climate, 21, 833-840.

Williamson, D. L., and Coauthors, 2005: Moisture and temperature balances at the Atmospheric Radiation Measurement Southern Great Plains Site in forecasts with the Community Atmosphere Model (CAM2). J. Geophys. Res., 110, D15S16, doi:10.1029/ 2004JD005109.

Winker, D. M., J. R. Pelon, and M. P. McCormick, 2003: The CALIPSO mission: Spaceborne lidar for observation of aerosols and clouds. Lidar Remote Sensing for Industry and Environment Monitoring III, U. N. Singh, T. Itabe, and Z. Liu, Eds., International Society for Optical Engineering (SPIE Proceedings, Vol. 4893), 1-11, doi:10.1117/12.466539.

Xie, S., M. Zhang, J. S. Boyle, R. T. Cederwall, G. L. Potter, and W. Lin, 2004: Impact of a revised convective triggering mechanism on Community Atmosphere Model, Version 2, simulations: Results from short-range weather forecasts. J. Geophys. Res., 109, D14102, doi:10.1029/2004JD004692.

Zhang, G. J., and N. A. McFarlane, 1995: Sensitivity of climate simulations to the parameterization of cumulus convection in the Canadian Climate Center general circulation model. Atmos.-Ocean, 33, 407-446.

Zhang, M. H., and Coauthors, 2005: Comparing clouds and their seasonal variations in 10 atmospheric general circulation models with satellite measurements. J. Geophys. Res., 110, D15S02, doi:10.1029/2004JD005021. 